\title{
Experimental analysis and Study on Shear Performances of Castellated Beam Chassis under Three Cases of Stiffener
}

DOI:10.36909/jer.11907

\author{
N. kumaragurubaran*, Dr. R. Subramanian, Dr. K. Jagadeesan
}

Assistant Professor, Department of Mechanical Engineering, Salem College of Engineering and Technology, Salem, Tamilnadu, India

Professor \& Head, Department of Automobile Engineering, Institute of Road and Transport Technology, Erode.

Professor, Department of Civil Engineering, Sona College of Technology, Salem - 636005 *scholar.kumaragurubaran213@gmail.com

\begin{abstract}
Nowadays, Engineers are actively seeking to improve construction materials and properties. In that, the usage of the castellated beam is become very popular due to its advantageous structural applications. In existing researches are described the presence of large openings in the web that creates different mechanical behaviour compared to strong web beams. While it does not deal with the behaviour of the shear strength performances of the castellated beam, which is due to the limitations on maximum allowable deflections by welding stiffeners. Therefore, this research analysis intends on augmentation of shear strength in castellated beam. Hence, the work incorporates shear stiffeners along with the web opening of the web adjacent to the shear region. Consequently, it leads to increase the shear strength of the castellated beam chassis with regard to cyclic loading and also efficiently reduce the deflection. In order to improve the behaviour of the castellated chassis beam, the study investigation providing the diagonal stiffeners on the web opening with the shear zone and thus compared to without stiffeners and vertical stiffeners. At last castellated beam and deflection effects with increased depth of web openings are analysed with the aid of Finite Element Analysis software ANSYS 16.0. From the experimental findings, the paper achieves
\end{abstract}


the maximum deflection of forwarding and reverse cyclic loading is $7.7 \mathrm{~mm}$ and $7.29 \mathrm{~mm}$ respectively. This demonstrates the efficacy and the confines of the assorted studies of stiffening solutions.

Keywords: Castellated beam, Chassis, Stiffener, Shear Strength, Indian Standard MediumWeight Beams (ISMB), without stiffener (WOS), with diagonal stiffener (WDS).

\section{INTRODUCTION}

Engineers are actively seeking to improve the architecture of building materials of practices. One such development occurred in mid-1930 built-up structural parts, being castellated beam by an engineer working in Argentina, Geoffrey Murray Boyd. Beams that are supported with web section opening are more like castellated beams [Sudarshan Kale, Vishwajeet Kadlag, et al., (2018)]. Specifically, the opening given for castellated beams is circular or hexagonal openings that are scattered on the web portion of castellated beams at [Jamadar, Kumbhar, (2015)] frequent intervals. They are made from hot-rolled I-section which is cut into certain lines and then both halves are moved and re-welded in such a way as to increase their size. The portion of the beam collected is 50 per cent deeper than the parent I-Section which is 1.5 times the initial portion depth [Patil, Kumbhar, (2016)]. Both long-span structures and vibration characteristics are better suited with a castellated beam. The high strength properties of structural steel cannot always be used to the greatest advantage because of the limitations on the smallest amount of allowable deflection. As a result, several new methods [Tsavdaridis, Galiatsatos, (2015)] aimed to increase steel member stiffness, without requiring any increase in steel weight. Some of the best options is a castled mirror.

Re-routing services (or increasing floor height to accommodate them at the design stage) contributes to increased costs and is usually undesirable. The provision of web-opening beams has become an acceptable engineering method and removes the possibility that a service engineer [Amin Mohebkhah, Mojtaba, (2015)] will cut holes in inappropriate locations 
afterwards. In these situations, beams with web openings may be advantageous as there are other alternatives available to solid web beams such as stub girders, trusses, etc. This method of construction retains a smaller depth of construction with services being put inside the girder width [Delphine Sonck, Jan Belis, (2015)], at the most suitable locations. The creation of an opening in the beam's network changes the stress distribution within the member and also influences its actions to collapse.

Castellated beams are categorized as openings created in the portion of the web according to their shape. Most common opening shapes [Konstantinos Daniel Tsavdaridis, James, et al., (2015)] are hexagonal, circular shapes often called cell opening, octagonal, diamond etc. However, mainly hexagonal and circular openings of beams are used in industries due to simplicity [Durif, Bouchair, (2016)] in manufacturing. In addition, most work is performed on optimizing hexagonal and circular form. In the castellated beam, the stiffener is the structural elements used to improve shear and moment resistance [(2017)] of steel plates along the longitudinal, coupling or/and opening side. But if the castellated beams are subjected to intense loading (such as Gantry girders) then castellated [Badke-Neto, Calenzani, et al., (2015)] beam appears to be unacceptable in such situations. In these cases, castellated beams at the positions where these concentrations of load occur must be reinforced. For example, by additional fitting and welding work, inserting plates called stiffeners [Ellobody, Young, (2015)] into one or more of the web openings. It is noted that, if a stiffener is installed, there is no controlled awareness of how a beam with web openings will behave.

The presence of the holes in the web, however, will change the beam's structural behaviour from that of plain webbed beams. Investigational tests on castellated beams have shown that the key parameters are beam slenderness, castellation parameters [Erdal, Tunca, et al., (2015)] and load type which determines the strength and failure modes of these beams. For many years, castellated beams have been used in building. Today these beams are manufactured in 
an almost infinite number of depths and spans [Gao, Gao, et al., (2019)] suitable for both light and heavy loading conditions with the production of automated cutting and welding equipment. The cutting angle of castellated beams in the past ranged from 45 degrees to 70 degrees but currently, 60 degrees has become a relatively common cutting angle, though there are still 45-degree parts available [Jovic, (2015)]. It should be remembered that these are estimated measurements [Kim, Li, et al., (2016)], to satisfy certain geometrical criteria, the real angles can differ significantly from those.

Among that there are certain drawbacks in the use of castellated beams as chassis in vehicles, due to the presence of holes in the network, castellated beams ' mechanical behaviour [Kwani, Wijaya, (2017)] varies from that of simple webbed beams. Possible modes of failure or even new modes of failure [Martins, Fer-reira, et al., (2017)] that occur in castellated beams are highly indeterminate because it is difficult to foresee the forces acting on the castellated Beam. Simple methods used to evaluate castellated beam behaviour do not produce exact results. Therefore, it includes sophisticated [Panedpojaman, (2015)] systematic analysis. Castellated beam behaviour should be analysed using various analytical methods and the findings should be correlated. Castellated beam has certain drawbacks [Pourbehi, Pirmoz, (2015)] to it. For example, near the perforations stress concentration is observed and hence the beam's shear carrying capacity [Yuan, Yu, et al., (2016)] is decreased. The stresses are typically slight near the neutral axis. Through having perforations along the neutral axis [Setiyawan, Maimunah, et al., (2019)], the stress concentration can be reduced; the holes are cut in a zigzag way.

The necessity for the present study emerges from the need to improve the output of the castellated beam specifically under the shear stress of cyclic loading, with and without stiffeners. Then the aims of the present research are to study the strength features of the castellated beam as chassis in automotive trucks. And to assess the effective size and shape of 
web openings that are subject to static and dynamic load conditions in the castellated beam. Then formulate an appropriate method for producing castellated beams from the use of traditional steel beams and the weld joints in the castellated beam network are built. At last, the work assesses the load-carrying capacity of castellated beams under cyclic loading with and without stiffeners.

\section{LITERATURE SURVEY}

Setiyawan et al [Setiyawan, Maimunah, et al., (2019)] Using a diagonal stiffener in a castellated steel beam full-height rectangular opening will avoid vierendeel's failure mechanism. This results in the castellated beam's flexural ability higher than the original section of the IWF. Bending the hole width on the web section will maximize the flexural potential of a castellated steel plate. This work aims at finding out the effect of multiple castellated steel beam hole width values on the flexural power. There are 4 castellated steel beam models in this study, the flexural capacity values of which are measured using truss analysis and pushover analysis methods.

Al-Thabhawee et al [Al-Thabhawee, Mohammed, (2019)] this study focused on improving the behaviour of the castellated beam using steel ring stiffener with octagonal openings and determining the best dimensions and distribution for the stiffeners. All specimen models were manufactured from section parent I (IPE 140). The models were modelled and analysed using ANSYS finite element software (version 15). Results of the study showed that reinforcing octagonal castellated beams by inserting steel ring stiffeners around octagonal web opening was a very active way to increase the ultimate long span load, where the ultimate load of reinforced octagonal castellated beam increased by up to (286 per cent) compared to parent Isection beam. Economically, as compared to the weight of parent I-section beam, the amount of additional steel content used to extend and strengthen the castellated beams (spacer plate and steel ring stiffeners) was (36 per cent). The gained advantage was to raise the ultimate and 
allowable load of reinforced octagonal castellated beams by (186 per cent) and (160 per cent) respectively by using additional steel material only (36 per cent) from the weight of the parent I-segment, which consisted of the spacer plates and steel rings for additional steel material. The findings also show that the best measurements for the ring were when the thickness corresponded to the parent section's web thickness and the width equal to half the parent section's flange width.

Anupriya et al [Anupriya, Jagadeesan, et al., (2016)] the strength properties and mechanical behaviour of castellated beams conforming to Indian Standard Medium Beam (ISMB) under static charging via finite element analysis were investigated. ANSYS 14.0 software was used to distinguish the trends of failure. Castellated beam deflection was noted under uniformly applied transverse tension. Different shapes were adopted for the openings on the web. Parametric analysis was performed by simulating various deflection patterns and by adjusting the size of the beam segment under static load. Investigation findings showed that diamondshaped openings in the network increased the strength characteristics of the castellated beam. Sahar et al [Sahar Elaiwi, Boksun, et al., (2019)] the purpose of this paper is to investigate the effect of web openings on castellated beams ' lateral-torsional buckling resistance, using both analytical and numerical methods. The analytical approach is designed based on the concept of minimum potential energy, while the analytical solutions are validated by elastic and inelastic numerical solutions obtained using ANSYS software. The investigations are carried out by applying uniformly distributed transverse loading on a castellated beam's top flange, with common boundary conditions. The analytical solutions developed can be used for both design and practical use.

Stalin et al [Stalin, Ravichandran, et al., (2019)] Development and study of the stringer in load-carrying vehicles are stated in this paper for the chassis frame. The frame must be a very hard one to withstand the vibration, twist and other stresses. Besides the weight, the frame 
should be able to withstand adequate bending and torsional rigidity. Here the work carried out by using finite element analysis tools to evaluate the stringer in chassis with the constraints of stiffness and strength. Results show that hat stringer when the stringer is in bending conditions is better than the C-stringer.

Al-Thabhawee et al [Al-Thabhawee, Al-Kannoon, (2018)] this study focuses on improving the behaviour of castellated hexagonal and octagonal beam with a spacer plate. The overall power of the initial (parent) I-section beam increases as its depth decreases. The increase of castellated beam depth; however, when these beams are subjected for processing, it contributes to post-buckling in its web and to several other modes of failure. Hexagonal and octagonal castellated beams made using parent I-section (IPN140) are analyzed using a finite element model (FEM). The results of the study revealed that the use of ring stiffeners around the edge of holes contributes effectively to strengthening the network. It was found that using ring steel stiffeners would reduce the concentration of stress around the edge of the holes and strengthen the behaviour of these beams by increasing the overall strength and reducing the deflection. From the numerical (FEM) results obtained by using ANSYS14, it is concluded that, by supplying a spacer plate and ring stiffeners around the web cavity, the ultimate strength of castellated beam can be increased. The findings also showed that the ultimate strength of the octagonal castellated steel beam can be increased to $(53 \%)$ higher than the parent beam (IPN140) with just (13.0\%) steel weight (spacer plate plus ring steel stiffeners).

Lei et al [Lei, Yuan, et al., (2017)] in this paper the problem of buckling axial compression of castellated columns about a major axis is investigated when exposed to a fire. An empirical method is derived for measuring the critical buckling load of castellated columns, which takes into account not only the shear effect of web openings but also the non-uniform cross-section temperature distribution due to non-symmetric fire exposure. The findings show that the critical buckling charge of a castellated column with non-uniform temperature distribution is 
smaller for the same average temperature than that of a castellated column with uniform temperature distribution. The web shear effect caused by web openings can significantly reduce the castellated column's critical buckling load, particularly for the columns with shorter lengths or wider flanges. However, the difference in the shear effect with different temperature distributions on the critical load is very small, and can generally be ignored.

From the review of literature on castellated beams, it is discovered that the shapes typically adopted for web openings are circular, rectangular, triangular, hexagonal and octagonal in castellated beams used as automotive chassis and other structural elements. In [Setiyawan, Maimunah, et al., (2019)] [Al-Thabhawee, Mohammed, (2019)] [Anupriya, Jagadeesan, et al., (2016)] have studied the behaviour of a castellated beam under static charge and cyclic loading. Both torsional and distortional web-post buckling is a common phenomenon which leads to castellated beam failure. Openings in a castellated beam's web in [Sahar Elaiwi, Boksun, et al., (2019)] [Stalin, Ravichandran, et al., (2019)] tend to decrease the rigidity of the castellated beam and create greater deflections than pure solid web beams. Plastic deformation controls the intensity of a beam. It is found that plastic deformation takes place at the openings and is caused by the moment and shear combined action, the web opening deepens, failure occurs. In [Al-Thabhawee, Al-Kannoon, (2018)] [Lei, Yuan, et al., (2017)] failure occurs due to stress concentration around the openings. These deficiencies can be resolved by supplying the openings near the neutral axis and making the cuts undulating.

\section{CASTELLATED BEAM FOR AUTOMOBILE CHASSIS}

Castellated beams are efficient load-carrying members in automobile trucks that are meant for heavy load applications. The use of castellated beam has been now admired because of beneficial functions like a light in weight, simple to build, economical and stronger. They can be readily handled and fastened. The most significant limitation experienced in castellated beams is the presence of holes in the web, although the mechanical behaviour of castellated 
beams varies from that of plain webbed beams. In existing research, potential failure modes or even new failure modes that occur in castellated beams are highly indeterminate in that the forces acting on the castellated beam are difficult to predict. And some basic methods used to evaluate the behaviour of castellated beams do not yield reliable results. It also requires sophisticated integrated research. The actions of castellated beams should be analysed using various methods of analysis and the findings should be compared. Thus, the stress concentration analysis is found near the perforation and therefore the shearing potential of the beam is decreased. In addition, most of the previous studies include stress levels near the neutral axis, which are normally small. The stress concentration can be minimised by supplying perforations near the neutral axis; the holes are zigzag-shaped. Usually, the transverse deflection and lateral- buckling of structural components is caused by dead loads and live loads such as building weight and human activities.

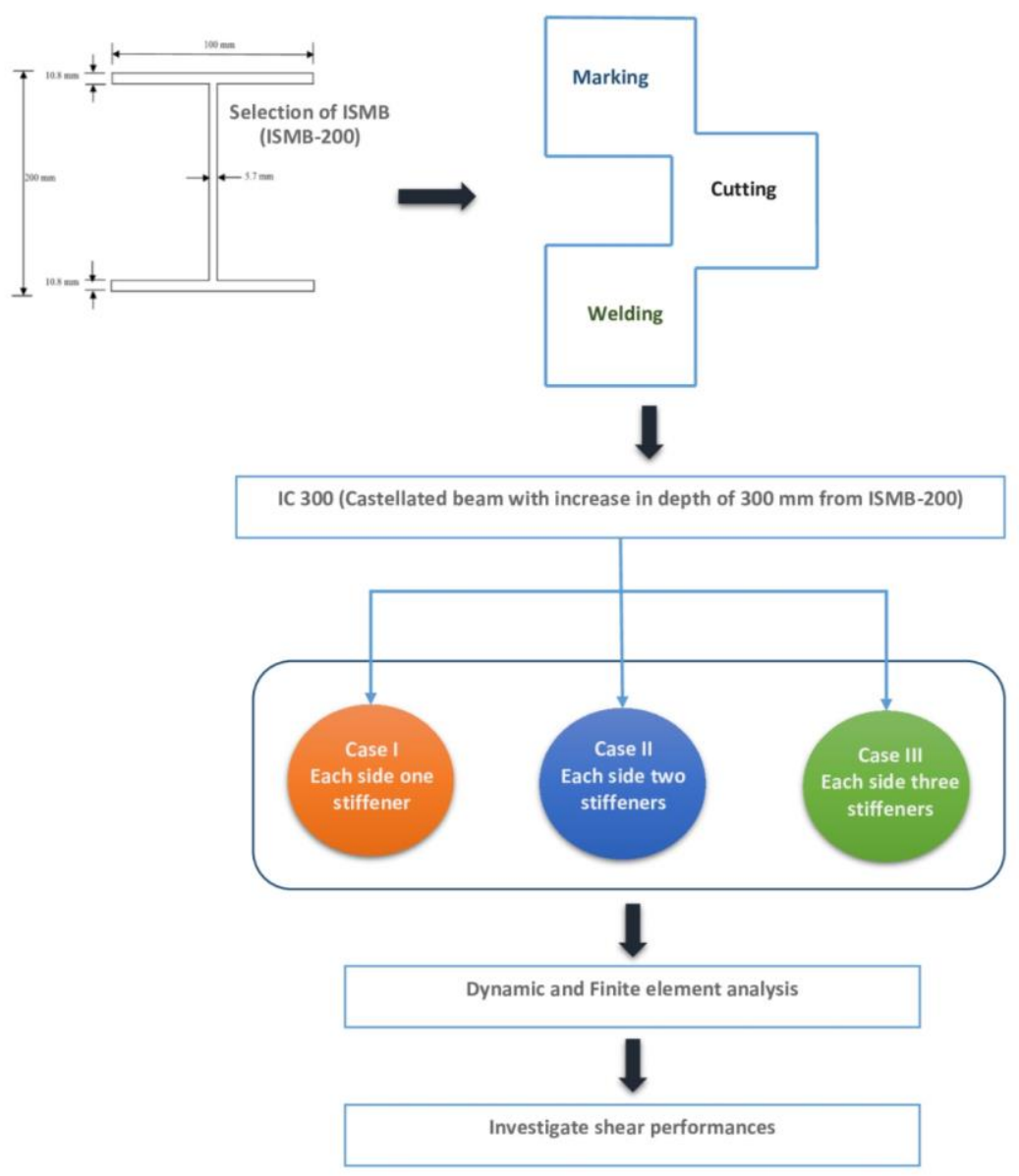


Figure 1 Investigation of castellated beam strength

The problem associated with transverse deflection and lateral- buckling in the structure of castellated beams is also affected by the network openings. The key serviceability requirements are generally to restrict deflection under a design load as a percentage of the beam's length (i.e., 1/250 where 1 is the beam length). Therefore, three separate things need to be addressed in the beam design process. The first issue is that the shear strength requires shear load power; the second is that the deflection consists of regulating the beam failure due to shear and the third is the lateral-torsional buckling. In figure 1 illustrates the overall investigation of shear performances of the castellated beam with three cases of stiffener placements. Castellated beams are used as structural components in multi-story buildings, commercial, industrial and portal frames. Castellated beams are not anything but castellated beams that are provided with potential in the site segment. The opening given for castellated beams is generally hexagonal-shaped openings, which are distributed at regular intervals on the web section of the castellated beam. Castellated beams are commonly used in steel construction as flexural parts. The inexpensive and structural advantages of such rudiments have led many researchers to examine the failure of these structures.

The need for this study arises from the requirement to improve the performance of castellated beams with and without stiffeners, especially under the shear stress of cyclic loading. Thus experimental analysis accomplished the investigation of shear performances for castellated beam specimens using Indian Standard Medium-Weight Beams (ISMB) with a depth of 200 mm. Consequently, the analysis of the research considers important goals, such as the evaluation of the strength characteristics of castellated beams as chassis in automotive trucks. And estimates the effective size and shape of the web openings in the castellated beam are subjected to static and dynamic loading a condition that improves the strength behaviour. The study then looked at the formulation of an effective method for the fabrication of castellated 
beams using traditional steel beams. Subsequently, the design of the welding joints in the web of the castellated beam shall determine the load-bearing capacity of the castellated beam with and without the stiffeners subjected to shear force under cyclic loading. There are three types of specimens are developed in this paper that is on each side of the specimen with the provision of one stiffener, two stiffeners and three stiffeners. Then standard experimental tests are done by applying cyclic loads on the specimens. The results which include dynamic and finite analysis of the elements, at last, that is compared with the results of numerical analyses. The detail description of design and analysis of castellated beam strength is explained in the below sections.

\section{Design Procedure of Castellated Beam}

Two considerations are primary concern in beam design: (1) strength requirements, i.e. the beam has ample strength to withstand the applied bending moments and associated shear forces; and (2) stability concern, i.e. the component is secure against buckling. Many failure modes are likely to occur due to the opening in the network, which needs to be tested and prepared for. The intensity of a beam with various web openings can be determined based on the flexure and shear interaction at the web opening. Model constraints include the displacement limits, overall flexural beam ability, beam shear ability, overall beam buckling strength, web post-buckling, and upper and lower tee bending by Vierendeel. The elaborate details about steel section properties are followed.

\section{Properties of Steel Section}

In the present study, Indian Standard Medium-weight Beam (ISMB) - steel parts - with a depth of $200 \mathrm{~mm}$ has been used. The specimens are being rendered in compliance with Indian Standards Code-IS: 800-2007. Table 1is adopted with standard steel requirements. The specimen has been rendered as $3.1 \mathrm{~m}$ in circumference. Density $=7.85=10-6 \mathrm{~kg} / \mathrm{mm} 3$, Young's modulus $=200 \mathrm{MPa}$, Poisson's ratio $=0.3$, yield strength $=250 \mathrm{MPa}$, and ultimate 
strength $=460 \mathrm{MPa}$ have been tested to be the properties of structural steel.

Table 1 Mechanical properties of steel section

\begin{tabular}{|l|l|l|}
\hline Sl. No. & Properties & ISMB 200 \\
\hline 1 & Designation & ISMB 200 \\
\hline 2 & Weight per metre, $\mathrm{w}(\mathrm{kg})$ & 25.4 \\
\hline 3 & Sectional area, a $\left(\mathrm{cm}^{2}\right)$ & 32.33 \\
\hline 4 & Depth of section, $\mathrm{h}(\mathrm{mm})$ & 200 \\
\hline 5 & Width of a flange, $\mathrm{w}_{\mathrm{f}}(\mathrm{mm})$ & 100 \\
\hline 6 & The thickness of the flange, $\mathrm{t}_{\mathrm{f}}(\mathrm{mm})$ & 10.8 \\
\hline 7 & The thickness of the web, $\mathrm{t}_{\mathrm{w}}(\mathrm{mm})$ & 5.7 \\
\hline 8 & Moment of inertia, $\mathrm{I}_{\mathrm{xx}}\left(\mathrm{cm}^{4}\right)$ & 2235.4 \\
\hline 9 & Young's modulus $\left(\mathrm{N} / \mathrm{mm}^{2}\right)$ & $2 * 10^{5}$ \\
\hline 10 & Yield stress $(\mathrm{MPa})$ & 295 \\
\hline 11 & Ultimate stress $(\mathrm{MPa})$ & 426 \\
\hline 12 & Length of the beam, $1(\mathrm{~m})$ & 3.0 \\
\hline
\end{tabular}

Sections of steel used as auto chassis are made in rolling mills. The steel sections are classified on the basis of their cross- shape and thickness. Section shapes are specified by the types of members to be assembled, and to some extent on the installation process. In the current study, components of steel available locally are acquired.

\section{Process of castellation from ISMB 200}

The key advantage of castellated steel beam is that the beam's depth is increased, and its strength is increased without any weight gain. Castellation in a beam helps to optimize the beam's load-bearing capacity; it also optimally utilizes steel. Based on the castellated beam production process, the depth of the beam and the strength of the beam can be improved by using the same quantity or less of steel. One form of the extended beam is a castellated beam. Standard rolled form steel is extended by supplying holes in the beam's network. The holes are formed in such a manner that they create a normal pattern. From this pattern of the web, openings have derived the word 'castellated.' It can be recalled that for ventilation, illumination, observation, and positioning weapons ancient majestic castles were built with battlements or standard holes in the walls. Figure 2 is a representation of a castellated beam. 


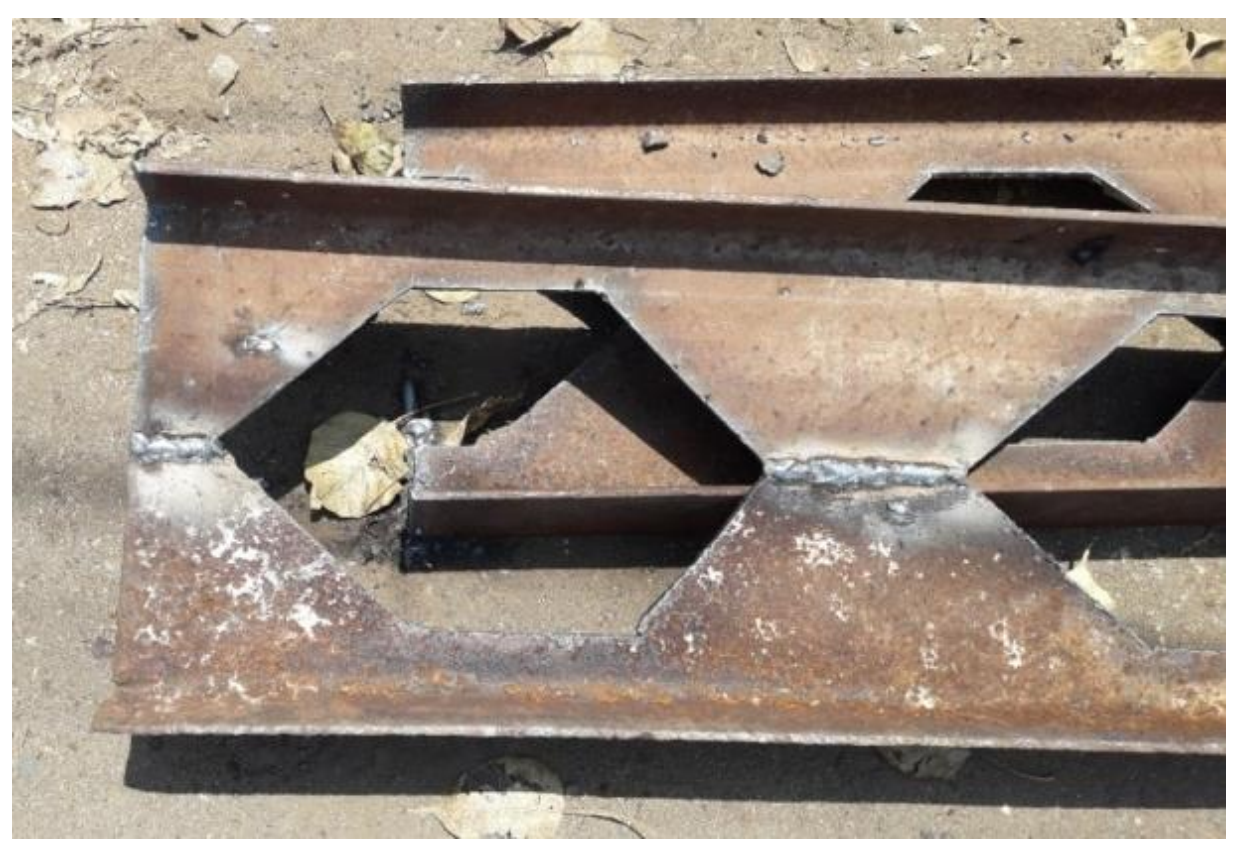

Figure 2 Illustration of the castellated beam

Longitudinally the steel segment is bifurcated into two halves by cutting the web into a regular alternating pattern of web holes. The halves are combined by welding after one part has been offset so that the high points of the web pattern come into contact with each other. For some castellated beam applications, the depth of the web hole can become important. This can be achieved by inserting web plates between T-section high points. Such additional plates are referred to as 'increment plates.' In castellated beam contains the different shapes for web openings, this research using the hexagonal shape of openings that is performed by utilizing the following sections.

\section{Methodologies for Castellation}

In this section, castellation of a beam from ISMB 200 design methodologies is analysed which is based on three terminologies. Thus it includes marking, cutting and welding, marking meant to pattern the shape of the design on steel, cutting is to separate the castellated beam with proper shape from steel. At last welding is joint the two web openings which form the beam of automobile chassis. The detail process of those terminologies are described in the below section and the illustration is in figure 3 . 


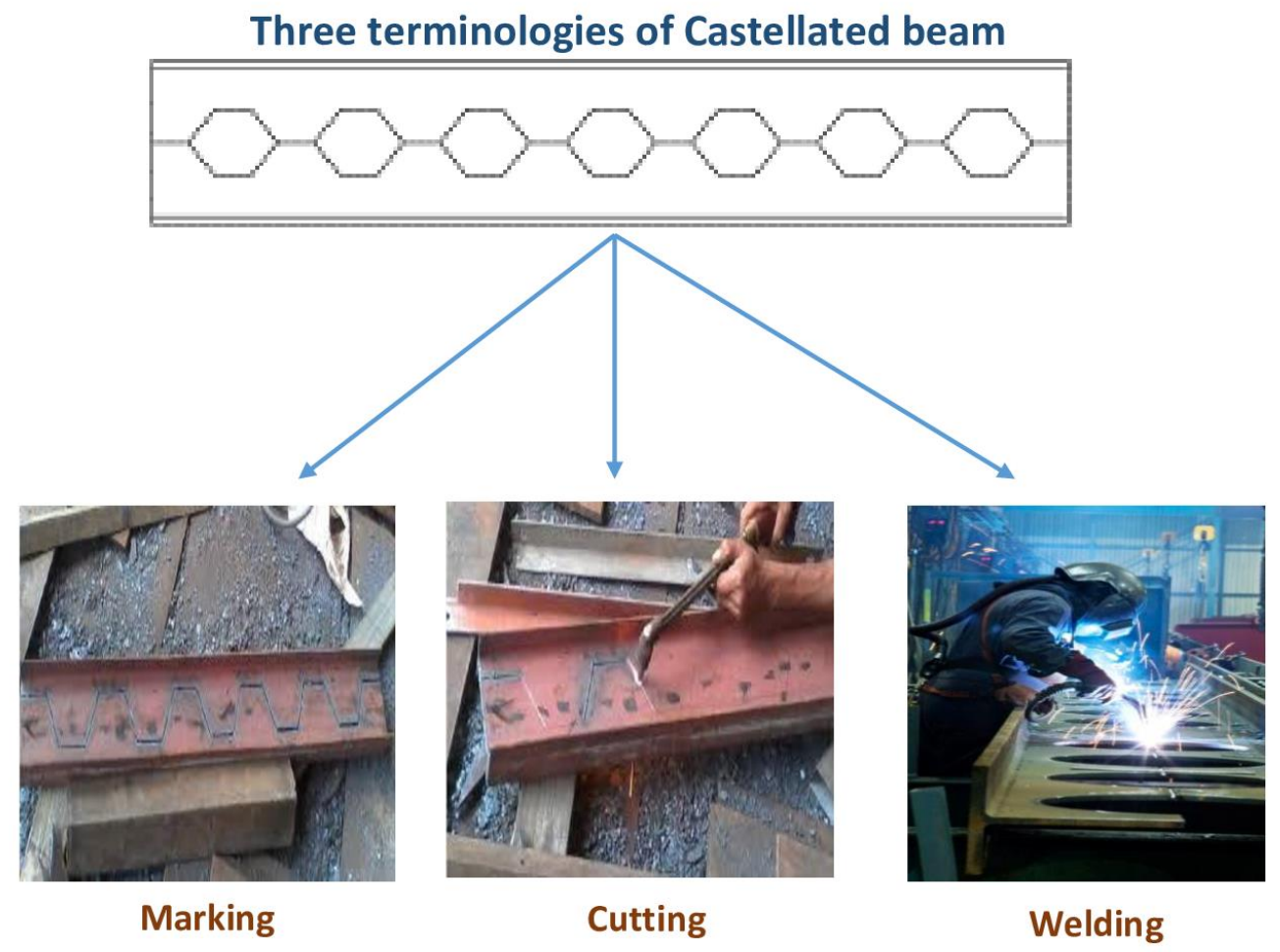

Figure 3 castellated beam terminologies

\section{Marking of Indian Standard Medium Beam Section for Castellation}

Steel section-ISMB $200 \mathrm{~mm}$ are made ready for the castellation process. Sections of steel were numbered as shown in Figures 4 and 5. The castellated beam specimens are produced to a maximum of $3 \mathrm{~m}$. As per normal dimensions, the web holes are cut at an angle of 450 along with the web in a zigzag fashion.
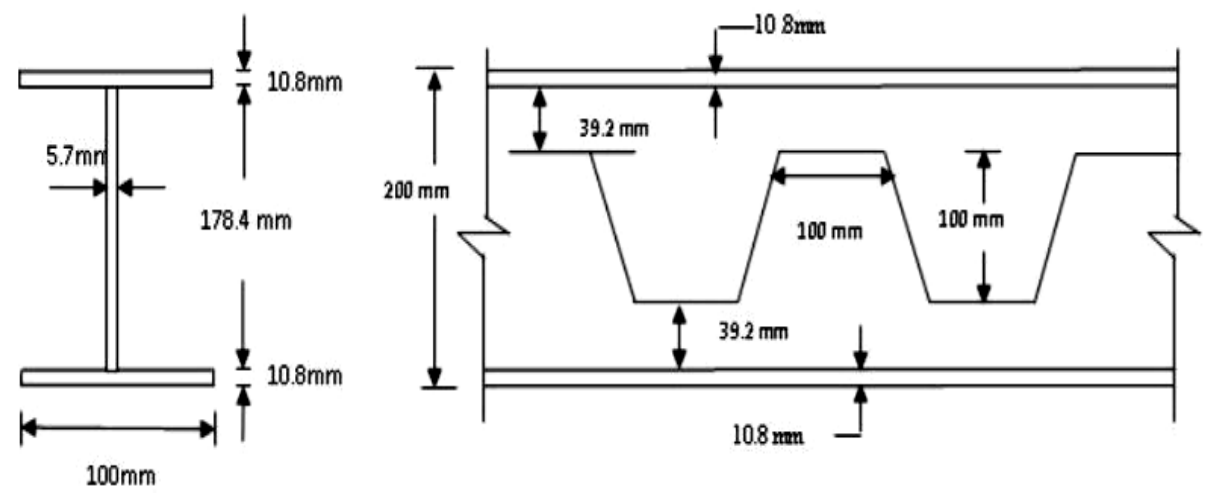

Figure 4 Dimensions of ISMB-200 steel section for castellation 


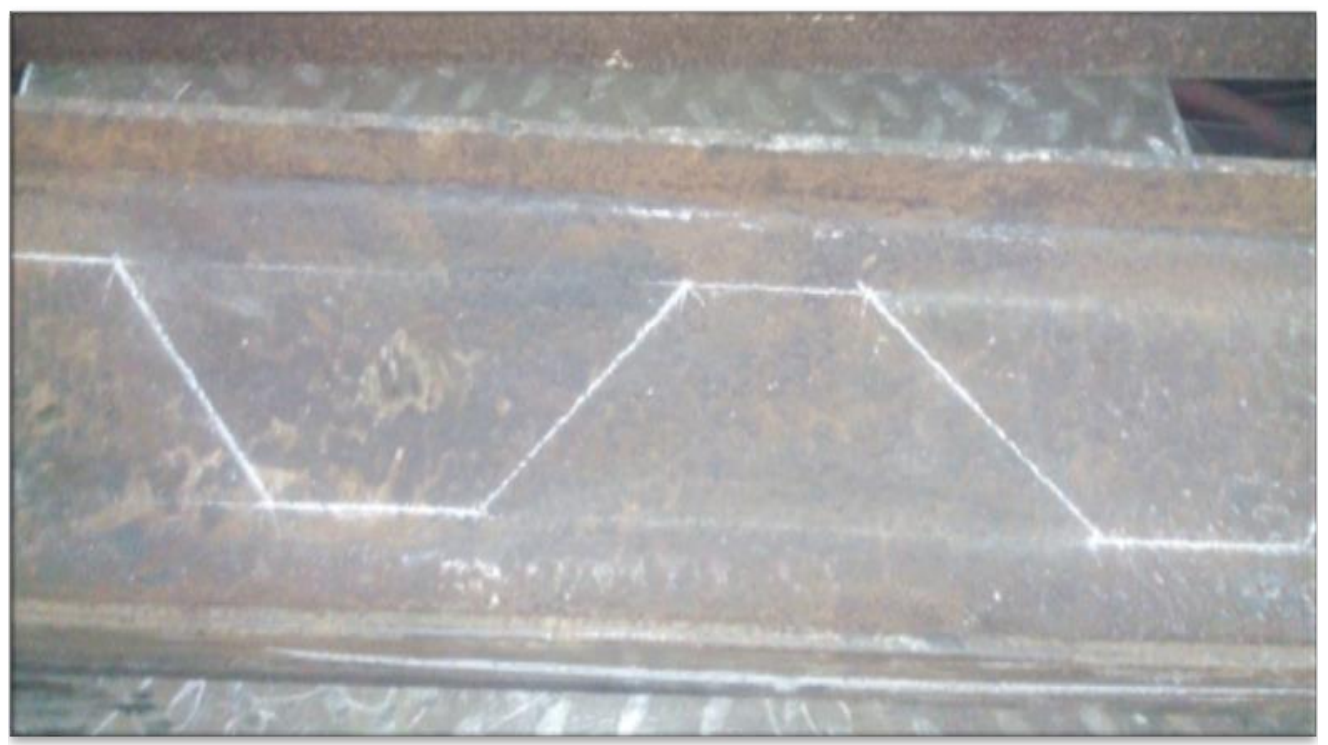

Figure 5 Marking of ISMB-200 section for castellation

Then after marking the particular shape like hexagonal, there is a needs to cut the shape for web openings in the castellated beam that is described in the next section.

\section{Cutting of Solid Steel Section for Castellation}

This section to analyse the cutting terminology of ISMB steel section is illustrated in figure 6 .

Here this paper using flame cutting is carried out on steel for castellation.

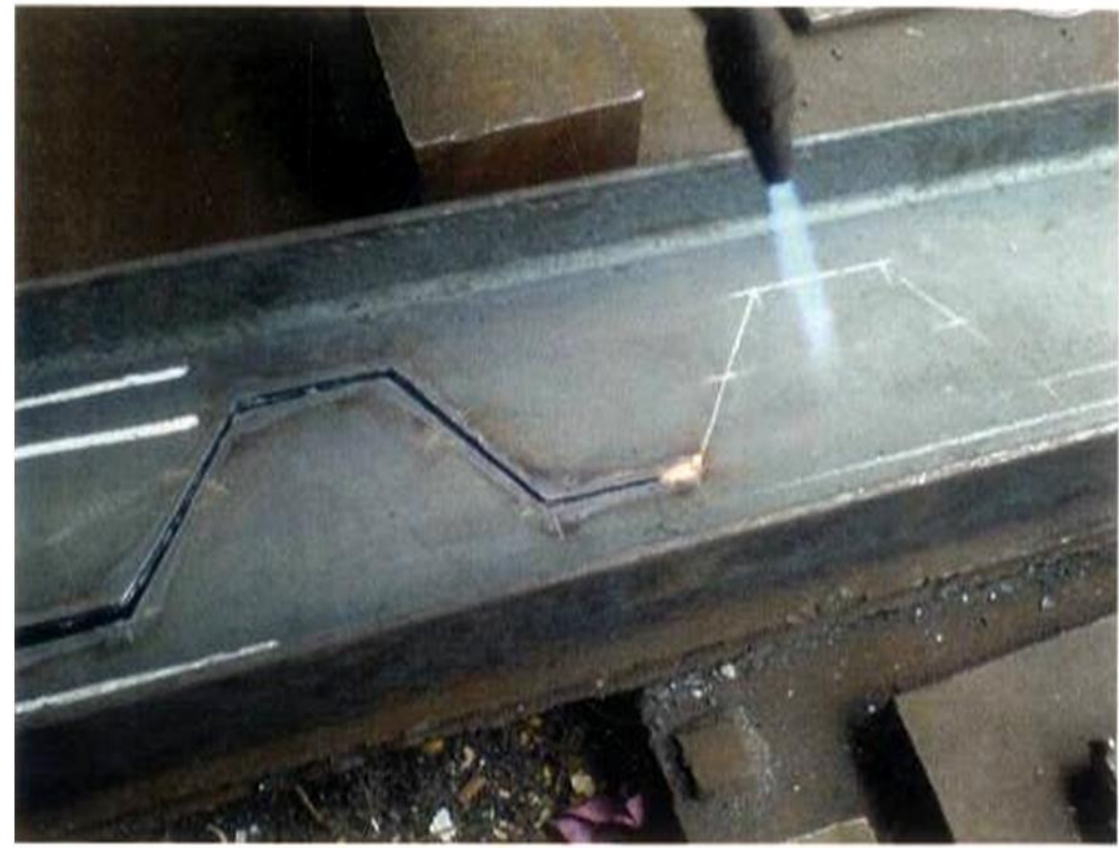

Figure 6 Flame cutting of ISMB steel section for castellation 
ISMB $200 \mathrm{~mm}$ steel parts are castellated in a zigzag manner with flame cutting along the web; the two halves are welded. The average depth is increased by 50 per cent with no weight gain. This factor helps to improve the beam's structural strength against bending.

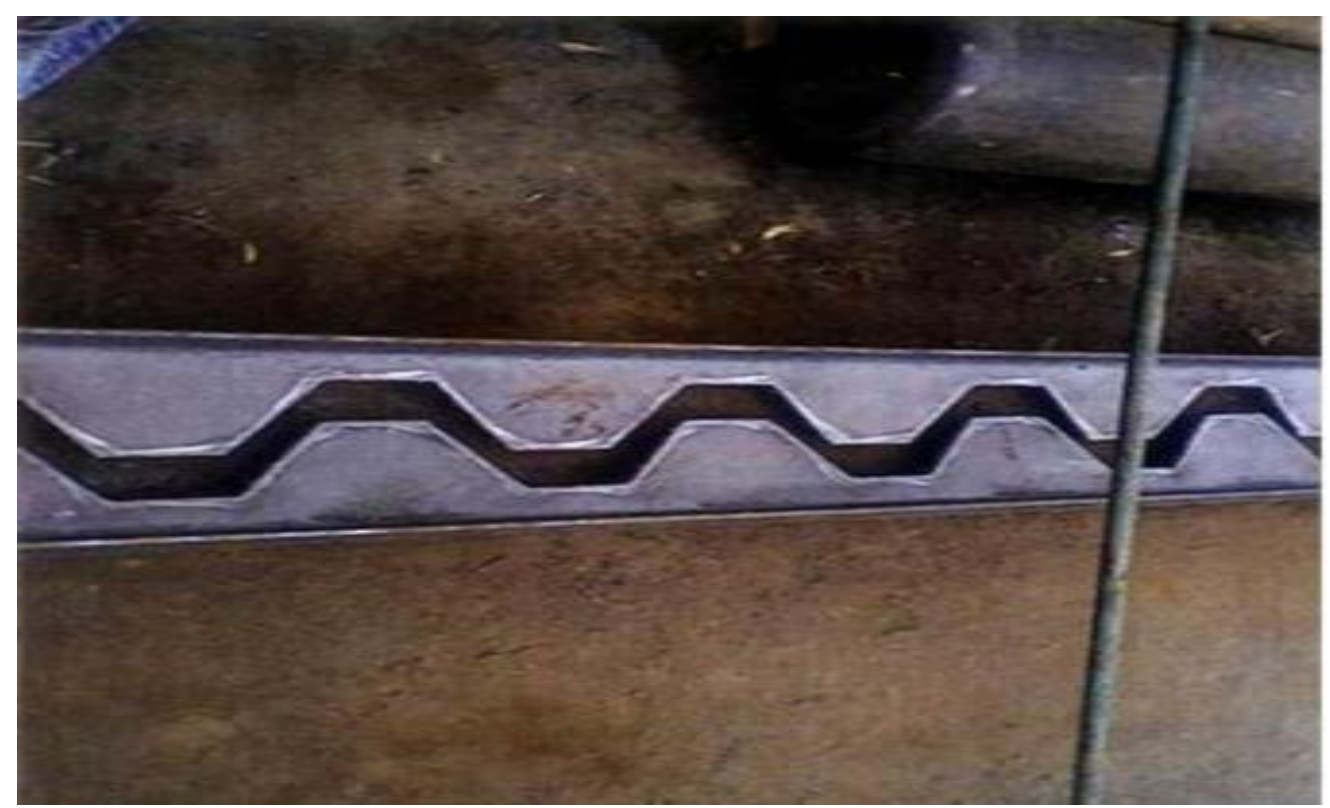

Figure 7 Two halves of ISMB steel section produced by flame cutting

Figure 7 shows the two halves of the steel section of the ISMB which are formed by flame cutting. After cutting the proper shape of the beam then to perform the welding for castellation.

\section{Welding of ISM for castellation}

Castellated beams are structural elements, which are created by flame cutting a rolling beam along with its web in a definite pattern and then connecting the two halves by welding so that the total beam depth is increased by 50 per cent without any weight increase for enhanced structural efficiency against bending. Figure 8 describes the process of castellation and the mathematical formulation of a castellated beam is given in Figure 9.

Due to its low cost and versatility in effecting a variety of temperatures, Shielded Metal Arc Welding (SMAW) is widely used in this research study for making structural connections. 
The electrode which is used in SMAW is stronger than the welded metal. The electrode used complied with IS specifications: 2879 , IS: 1395 , and IS: 814 . Reference was made to manual on Metal Arc Welding (MMA) and standard procedures were introduced, 410-grade steel welding was used in the current research work. This was done butt welding. Data were collected on weld yield strength and tensile strength, and taken as $330 \mathrm{MPa}$ and 410-510 $\mathrm{MPa}$ respectively.
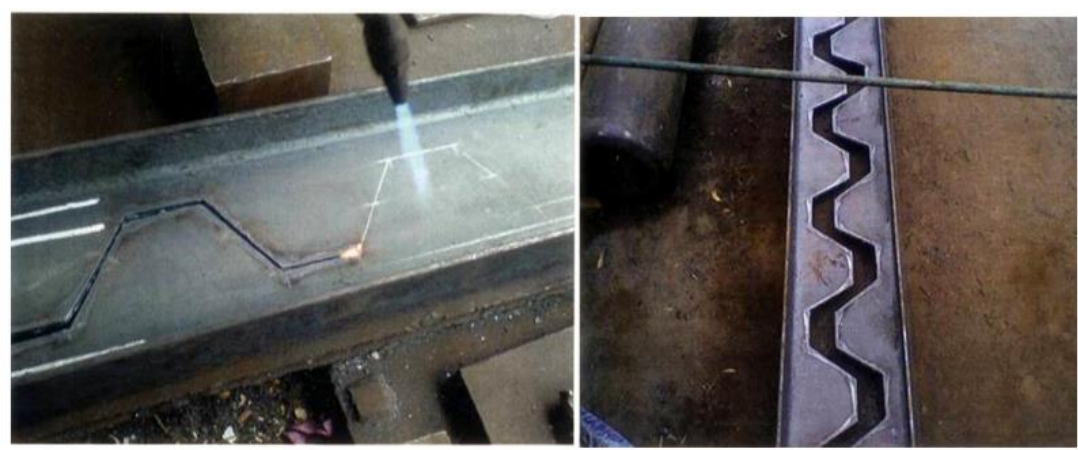

Figure 8 A process of welding on a castellation beam
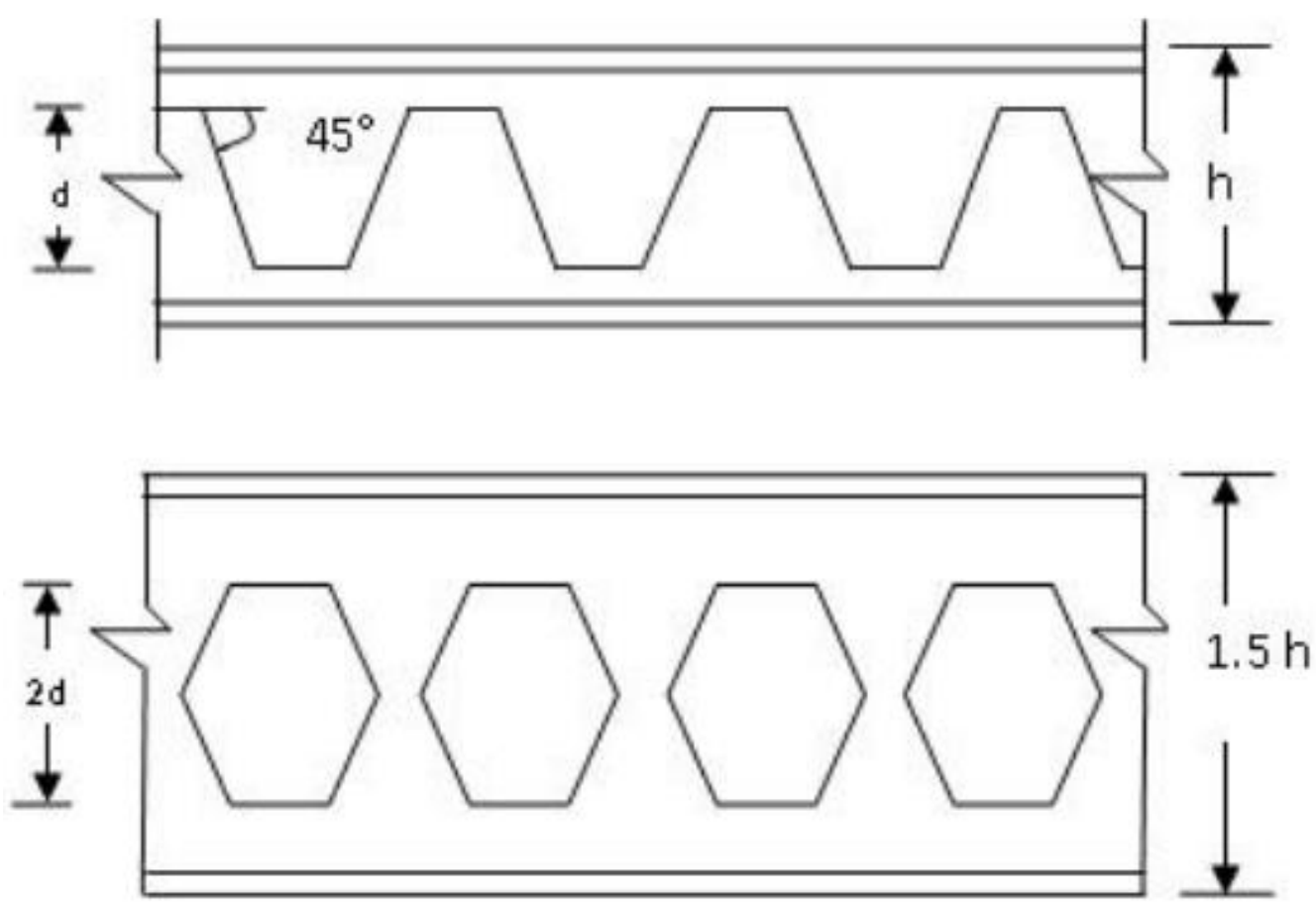

Figure 9 Mathematical formulation of the castellated beam

Load-Carrying Capacity of the Welded Joint with Respect to Shear 
Table 2 illustrates the load-carrying capability of the welded joint with respect to different forms of stress. The shear stress formed in the joining of the butt weld was taken as $150 \mathrm{MPa}$.

Table 2 Stress on butt weld joint

\begin{tabular}{|l|l|l|l|}
\hline \multirow{2}{*}{ Sl. No. } & \multirow{2}{*}{ Types of stress } & Stress on the welded joint (MPa) \\
\cline { 3 - 4 } & & Static as per IS: 800 (2007) & Fatigue \\
\hline 1 & Compression & 110 & 55 \\
\hline 2 & Tension & 100 & 55 \\
\hline 3 & Shear & 150 & 35 \\
\hline
\end{tabular}

The load-carrying capacity of the joint $V=\operatorname{tfx} \operatorname{Lwx} \tau$

Where $\mathrm{V}=$ load-carrying capacity of the joint in $\mathrm{kN}$

$\mathrm{tf}=$ thickness of the flange in $\mathrm{mm}$

$\mathrm{Lw}=$ length of the weld in $\mathrm{mm}$

$\tau=$ stress for the welded joint in MPa

Design and Determination of Shear Force on Welded Castellated Beam

The length of the beam is $3 \mathrm{~m}$ and the depth of the beam is $200 \mathrm{~mm}$. Maximum load of $81 \mathrm{kN}$ is applied at the Centre of the beam as shown in Figure 10.

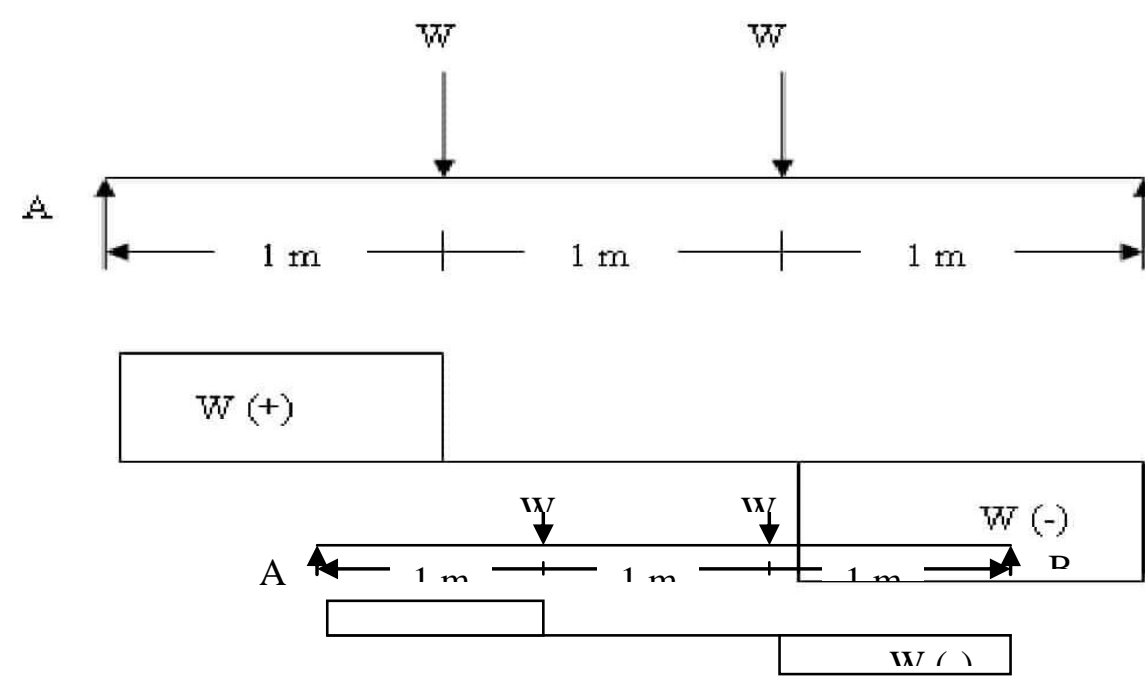

Figure 10 shear force acting on the castellated beam 
The load-carrying capacity of the joint under static shear,

$$
\begin{aligned}
V & =\quad t f \times L w \times \tau \\
& =5.7 \times 100 \times 150 \\
& =85.5 \mathrm{kN}>40.5 \mathrm{kN}
\end{aligned}
$$

The size of the butt weld made in this research work is $6 \mathrm{~mm}$. Details of welding are illustrated in Figure 11.

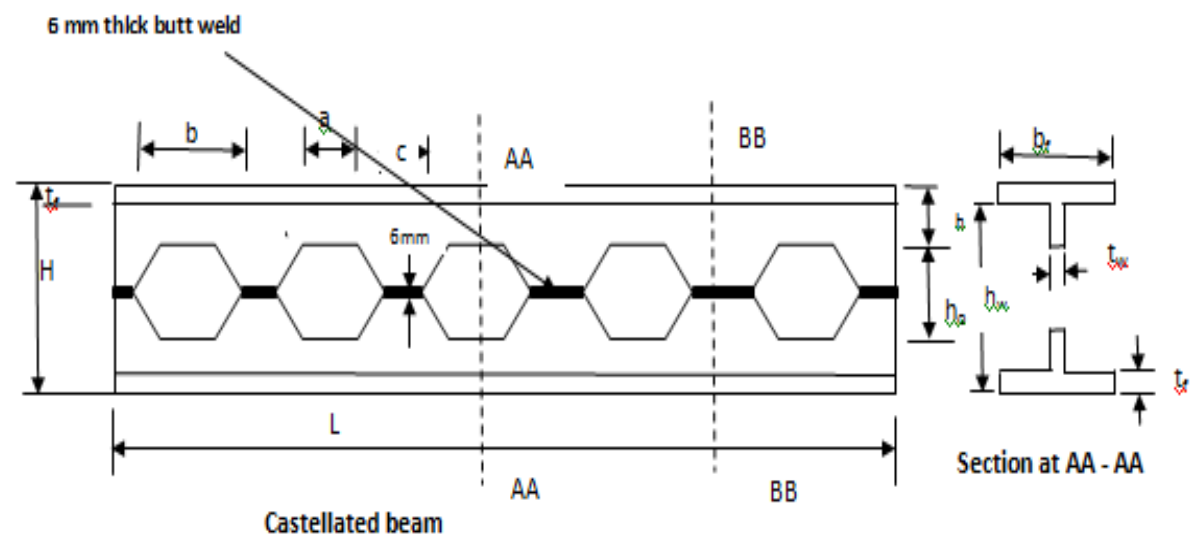

Figure 11 a process of welding on a castellated beam chassis

Finally based on the above three terminologies this research analysis performed the proper castellated beam design, therefore from that design this paper accomplished the fabrications.

\section{Fabrication of Castellated beam}

For fabricating the castellated beam from the cutter and welded joints of ISMB steel section. In the present research work, castellated beam specimens are prepared using ISMB 200 steel sections to carry out the experimental investigation. The steel pieces are cut in a specific pattern along with their web and then joined together to get an improvement in the depth of 50 per cent. ISMB castellated beam specimens made from ISMB 200 steel parts-known as IC.

The designations IC 300 apply to the increased depths from $200 \mathrm{~mm}$ (ISMB 200) to $300 \mathrm{~mm}$ of castellated beam specimens. The mechanical and geometric properties of the castellated beam specimens IC 300 are compared with those of ISMB 200 and described respectively in 
Tables 3. The dimensions of the castellated beam chassis specimens, IC 300 are illustrated in Figures 12 respectively.

Table 3 Properties of ISMB 200 and IC 300 castellated beam specimen

\begin{tabular}{|l|l|l|l|}
\hline Sl. No. & Properties & ISMB 200 & IC 300 \\
\hline 1 & Designation & ISMB 200 & IC 300 \\
\hline 2 & Weight per metre, $\mathrm{w}(\mathrm{kg})$ & 25.4 & 25.4 \\
\hline 3 & Sectional area, a $\left(\mathrm{cm}^{2}\right)$ & 32.33 & 32.33 \\
\hline 4 & Depth of section, $\mathrm{h}(\mathrm{mm})$ & $\mathbf{2 0 0}$ & $\mathbf{3 0 0}$ \\
\hline 5 & Width of the flange, $\mathrm{w}_{\mathrm{f}}(\mathrm{mm})$ & 100 & 100 \\
\hline 6 & The thickness of the flange, $\mathrm{t}_{\mathrm{f}}(\mathrm{mm})$ & 10.8 & 10.8 \\
\hline 7 & The thickness of the $\mathrm{web}, \mathrm{t}_{\mathrm{w}}(\mathrm{mm})$ & 5.7 & 5.7 \\
\hline 8 & Moment of inertia, $\mathrm{I}_{\mathrm{xx}}\left(\mathrm{cm}^{4}\right)$ & 2235.4 & 2235.4 \\
\hline 9 & Young's modulus $\left(\mathrm{N} / \mathrm{mm}^{2}\right)$ & $2 \square 10^{5}$ & 2 \\
\hline 10 & Yield stress $(\mathrm{MPa})$ & 295 & 295 \\
\hline 11 & Ultimate stress $(\mathrm{MPa})$ & 426 & 426 \\
\hline 12 & Length of the beam $(\mathrm{m})$ & 3.0 & 3.0 \\
\hline
\end{tabular}

In table 3 described the mechanical and geometrical properties of ISMB 200 and IC 300 castellated beam specimen. Thus it contains major properties such as weight per meter, depth of section, the width of flange, the thickness of the flange, the thickness of the web, a moment of inertia, young's modulus, yield stress, ultimate stress, and length of the beam respectively.
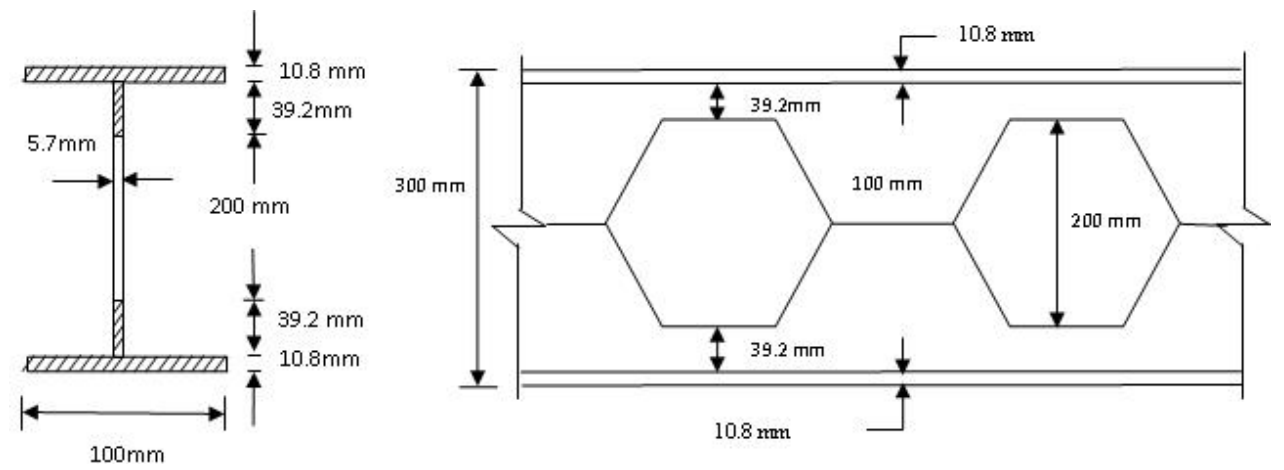

Figure 12 Dimensions of castellated beam chassis IC 300

Castellated beams were developed earlier, following basic handmade procedures. Castellated beams have for some time seen limited use. Although the methods of manufacture are not desirable for healthy growth, castellated beams have been recognized as beneficial structural members over the years. 


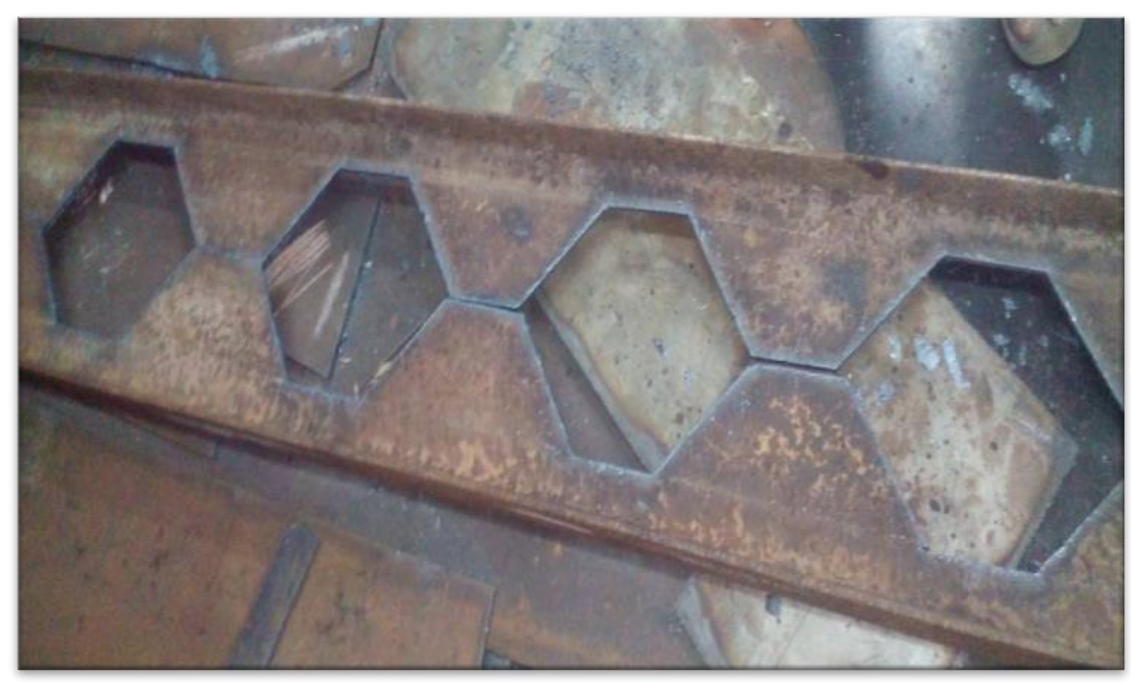

Figure 13 Castellated beam chassis with hexagonal holes

The holes pattern in a castellated beam's network provides a fine appearance. A typical castellated beam chassis specimen with hexagonal web openings appears in Figure 13 However, the web holes are practical provisions in that they facilitate the piping, conducting and ducting in modern automotive bodyworks. Then to place the stiffeners on the castellated beam this paper analyzed three cases that follow.

\section{Stiffeners placement in castellated beams chassis}

In the current work, castellated beam specimens are reinforced by supplying diagonally shaped stiffeners in the web holes. The stiffeners are made of $5 \mathrm{~mm}$ thick steel plate and a diameter of $25 \mathrm{~mm}$. providing stiffeners is intended to withstand shear force. The stiffeners are made available in three arrangement forms. In the first example, at each side of the beam, one stiffener is fastened in the link opening. For the second case, the castellated beam is strengthened on each side of the beam with stiffeners for two holes. In the third case stiffeners on each side of the beam are put in three holes. Figure 14 shows the arrangement of stiffeners in the holes of a castellated beam chassis. Figure 15 shows the drawing of the positioning of stiffeners in two web holes on each side of the beam. 


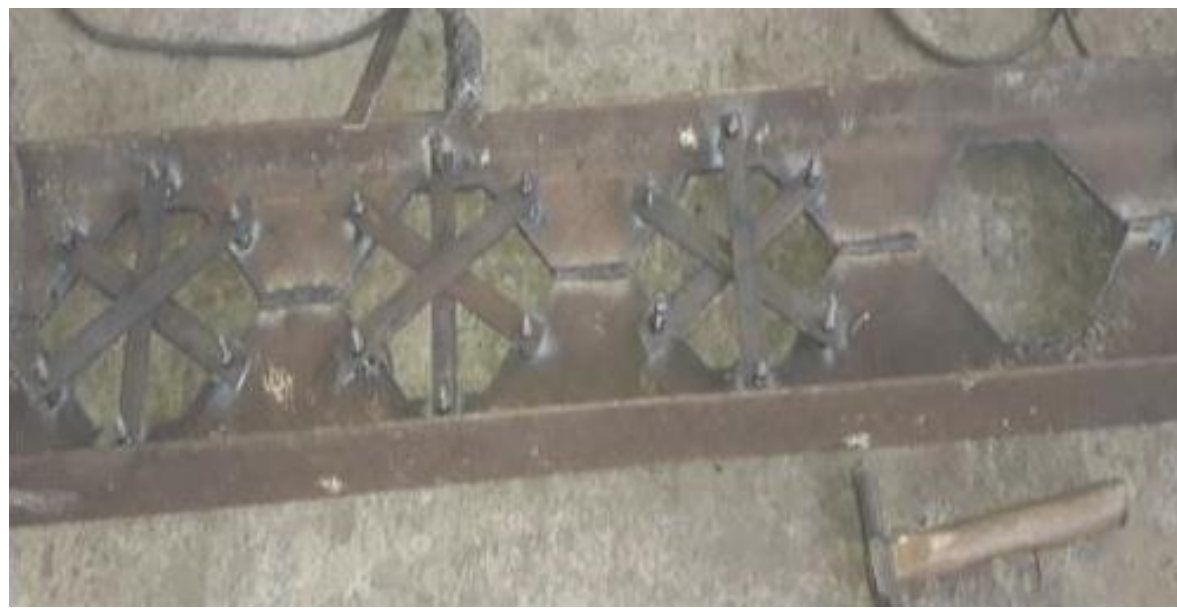

Figure 14 Stiffeners in Castellated Beams Chassis

The implementation of opening in one direction in a beam's network is a drawback as it affects the stress distribution within the member and impacts the beam failure. Openings within a beam's network appear to decrease the beam's rigidity. This results in significant deflections. Stiffeners are inserted in the web openings to increase the shear strength of a castellated beam and to reduce deflections. In the web holes, intermediate transverse stiffeners are given when the average shear stress is greater than the section's permissible buckling shear stress. Depending on the form and magnitude of loading on the beam specimens, the stiffeners may be supplied in pairs, one on each side of the cable, or in a single. Placing single stiffener on opposite ends of a castellated beam network is desirable. To resist compressive force, the intermediate stiffeners are classified as compression members. These also increase the buckling power of the slender web-facing shear force. As below, three stiffener configurations in web holes have been built in the castellated beam specimens, and tests have been performed.

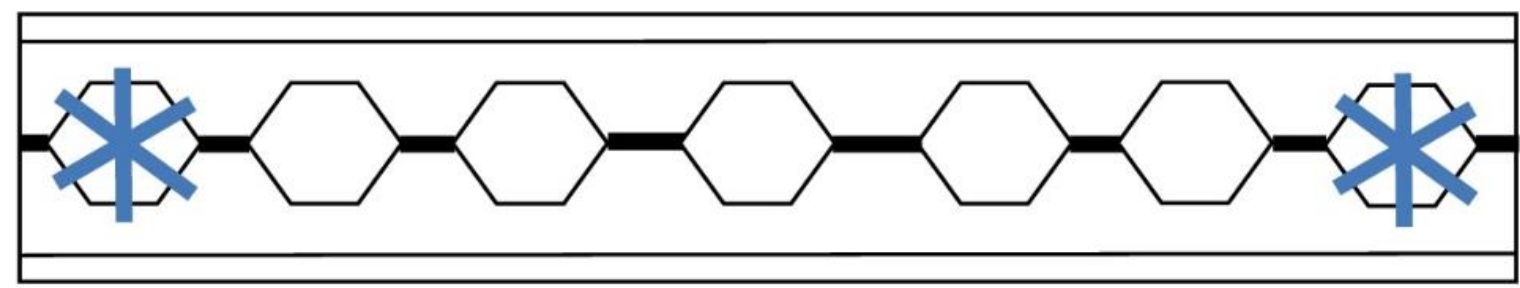

Figure 15 Stiffener in one web hole at each end of the beam chassis 
specimen

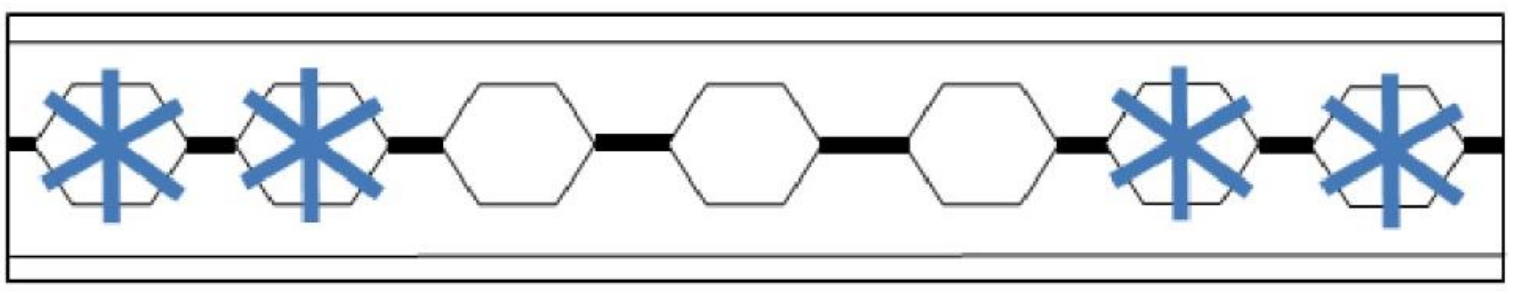

Figure 16 Stiffener in two adjacent web holes at each end of the beam chassis specimen

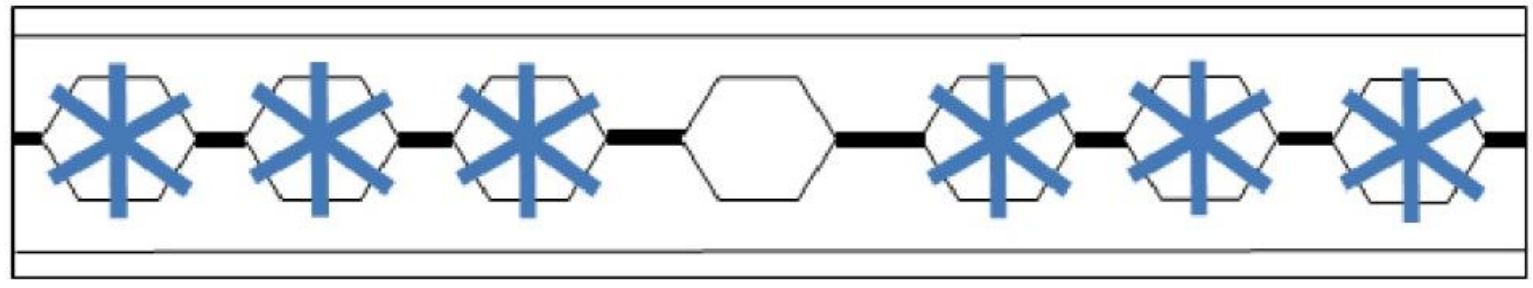

Figure 17 Stiffener in three consecutive web holes at each end of the beam chassis specimen

In figure 15-17 described the three cases of this research such as Stiffeners in one web hole at each end of the beam chassis specimen, Stiffeners in two adjacent web holes at each end of the beam chassis specimen, and Stiffeners in three consecutive web holes at each end of the beam chassis specimen respectively. Before the web opening the concentration of tension in the solid section is greater than the castellated beam, so the web openings have stiffeners to reduce the stress concentration. The web of castellated beam chassis specimens is provided in this research with seven openings.

Therefore from the above discussion, this paper effectively analyzed the design and fabrication of castellated beam with three cases of stiffener placements that enhance the shear and strength performances of beam chassis in automobile industries. The proficiency of the present research study and analysis is described experimentally in the upcoming section. 


\section{RESULT AND DISCUSSION}

Specimens of castellated beam chassis are constructed from ISMB 200 steel parts. The depth of the castellated beam frame specimens is composed of 1.5 times the solid section depth. Experimental experiments are carried out to test the strength characteristics of the castellated beam chassis specimens and their structural performance. This chapter addresses the experimental setup, load conditions, instrumentation to test the deflections.

\section{System Specification}

In this research analysis, the following system requirements are used for the implementation of the experimental study.

\begin{tabular}{|l|l|}
\hline Software & ANSYS-14.5 \\
\hline OS & Windows-7 \\
\hline CPU core & Core i8 \\
\hline
\end{tabular}

\section{Experimental Result}

Experimental studies are conducted on specimens of castellated beam chassis. The sequence activities of the experimental test program are initially to fabricate the castellated beam chassis specimens with required shape and dimensions. And the specimens are placed in the loading frame. Then support condition of the castellated beam chassis specimen is ensured. Here linear Variable Differential Transformer (LVDT) is placed on the specimen to measure the deflection. After that hydraulic jack is positioned at the middle of the loading frame to facilitate vertical and downward movements. Now the load is gradually applied, the deflections shown by the LVDT are recorded. At last, the load is applied until the failure of the specimen is realized. 


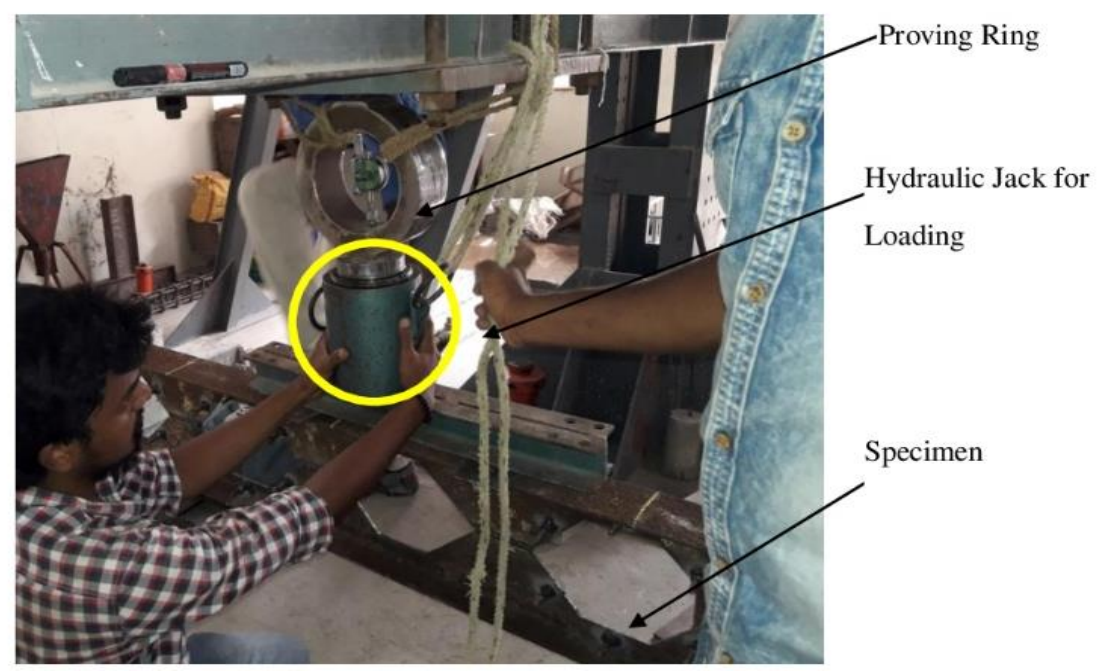

Figure 18 Testing the castellated beam

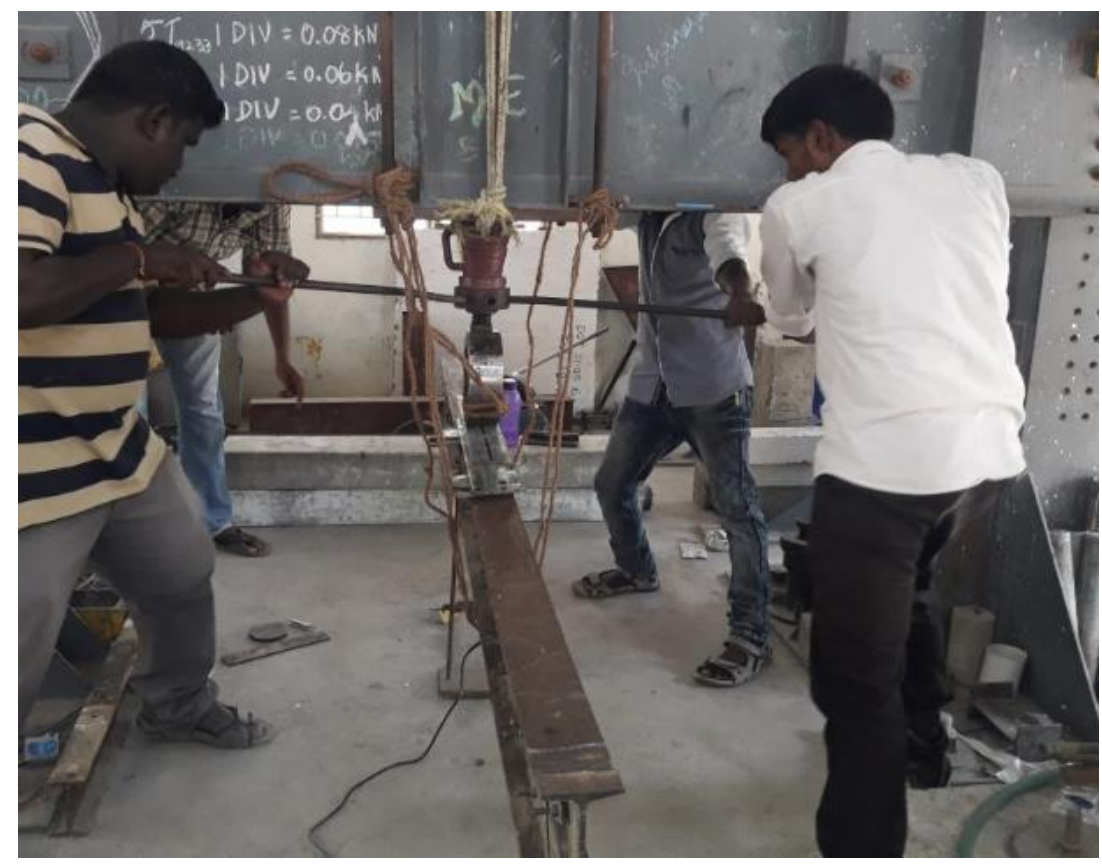

Figure 19 Loading of the castellated beam

Cyclic loading is applied on the castellated beam chassis specimen with both forward and reverse direction that is applied on three-time of cycles like the first cycle, second cycle, and third cycle which is illustrated in figure 18. And figure 19 described the first cycle of forwarding cyclic loading of the castellated beam chassis specimen IC 300 (Case-I). 


\section{Simulation Result}

This section described the simulation result of three cases and the properties of this research study. In figure 20 illustrates the case I that is a castellated beam with each side of one stiffener, figure 21 has shown the case II is a castellated beam with each side two stiffeners and figure 22 described the case III that is a castellated beam with each side three stiffeners respectively.

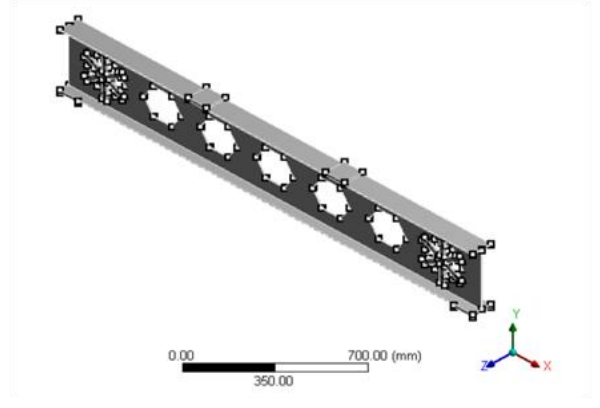

Figure: 20- a case I

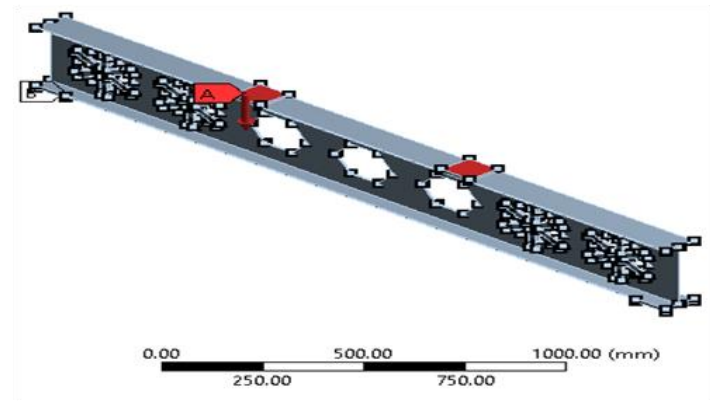

Figure: 21- a case II

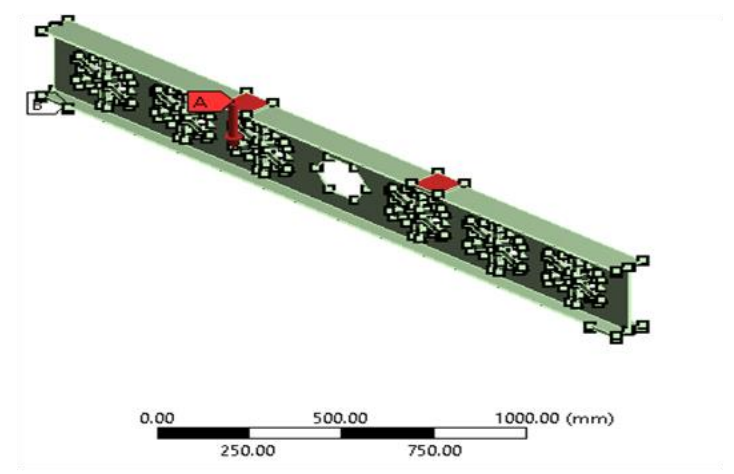

Figure: 22- a case III

\section{Load deflection behaviour of the beam}

Depending on the cyclic loading condition, the point load is applied to the beam on a supported beam with the same path and parameter constraint and the total beam displacement is calculated in this section. In order to accurately measure the deflection of the modular joint specimen, the difference between the strength of the reinforced concrete module and that of the concrete used for the joint is considered. The associated propagation length is reshaped as 
a new crack region in the specimen to represent the effects of the initial cracks in the joint.

This connection of the linked connection at the interface of the crack has been used to trigger the reinforced concrete's tension-stiffening action. That is described in the following section based on three cases.

\section{Deflection behaviour on case-1 with 3 cycles}

A specimen used in the castellated beam IC 300 and providing deflection data in the first case

(I) shown in the graph and analysed as ANSYS pictures for cycles 1, 2, 3 as shown in Figure 23.

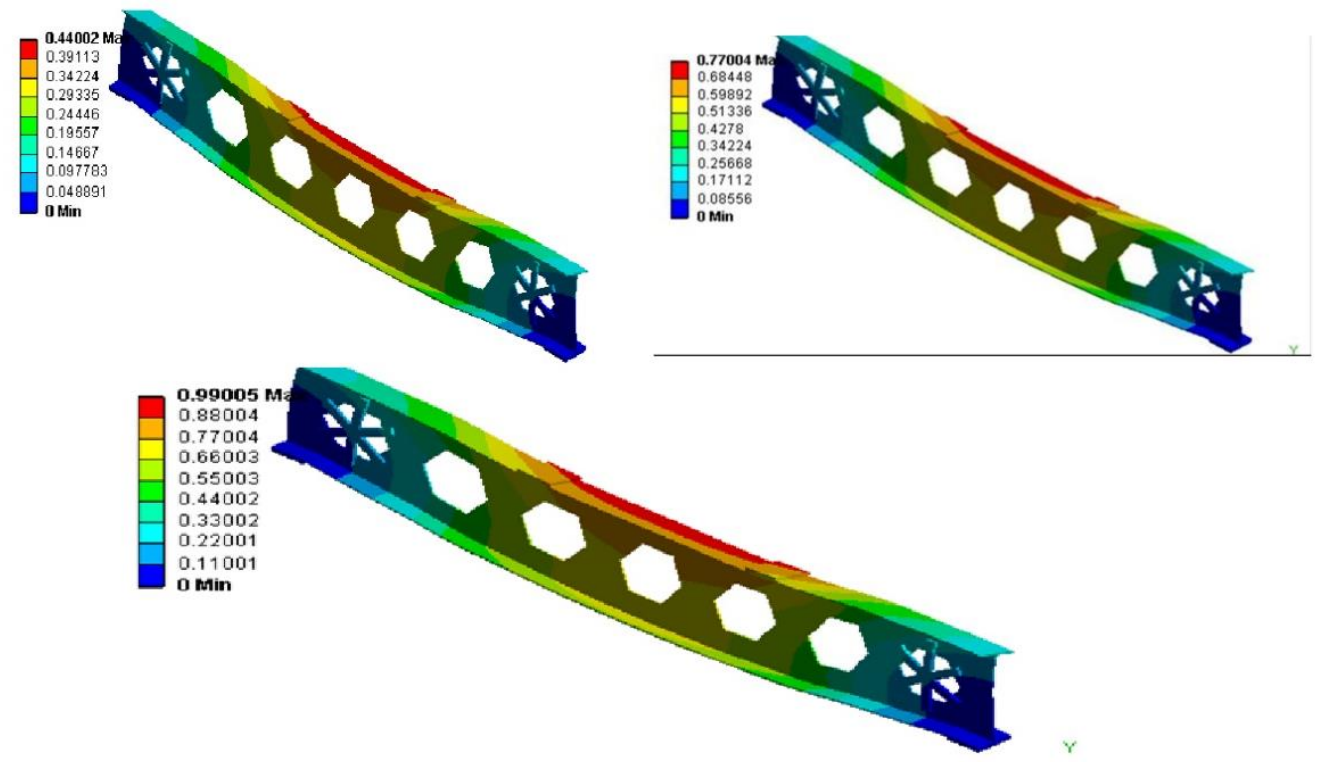

Figure 23 Deflection behaviour in case-1 and cycle -1, 2, 3

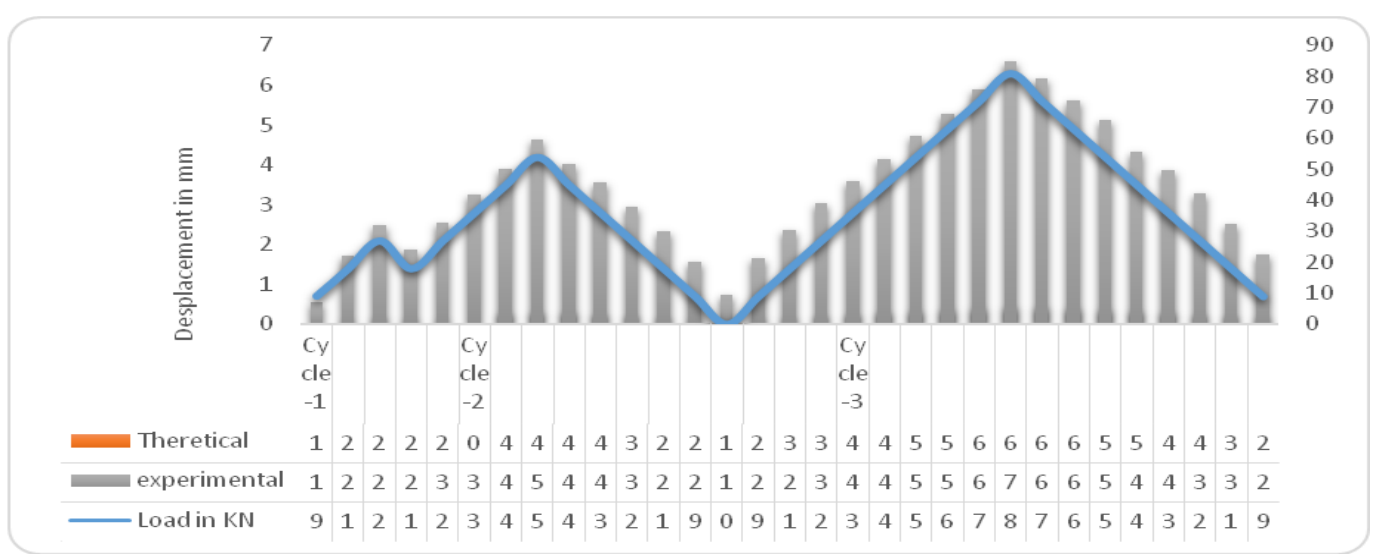

Figure 24 Graph analysis of deflection in case-1 and cycle -1, 2, 3 
Tension-stiffening is applied to the precast and joint interface in this study since the interface is essentially segregated by the maximum stress; therefore, only the attachment of the concrete and reinforcement may explain the behaviour of the flexible specimen. The graphical values of displacement behaviour with complete analysis of behavioural deformation in case 1, 2, and 3 is shown in Figure 24. It is based on the load and deflections deviation values for each event.

\section{Deflection behaviour on case-2 with 3 cycles}

The following graphs for case II are plotted between the deflection values of load Vs. A specimen used in the castellated beam IC 300 and provide in the second case deflection data seen in the graph and analysed as ANSYS images for cycles 1, 2, 3 as shown in Figures 25.

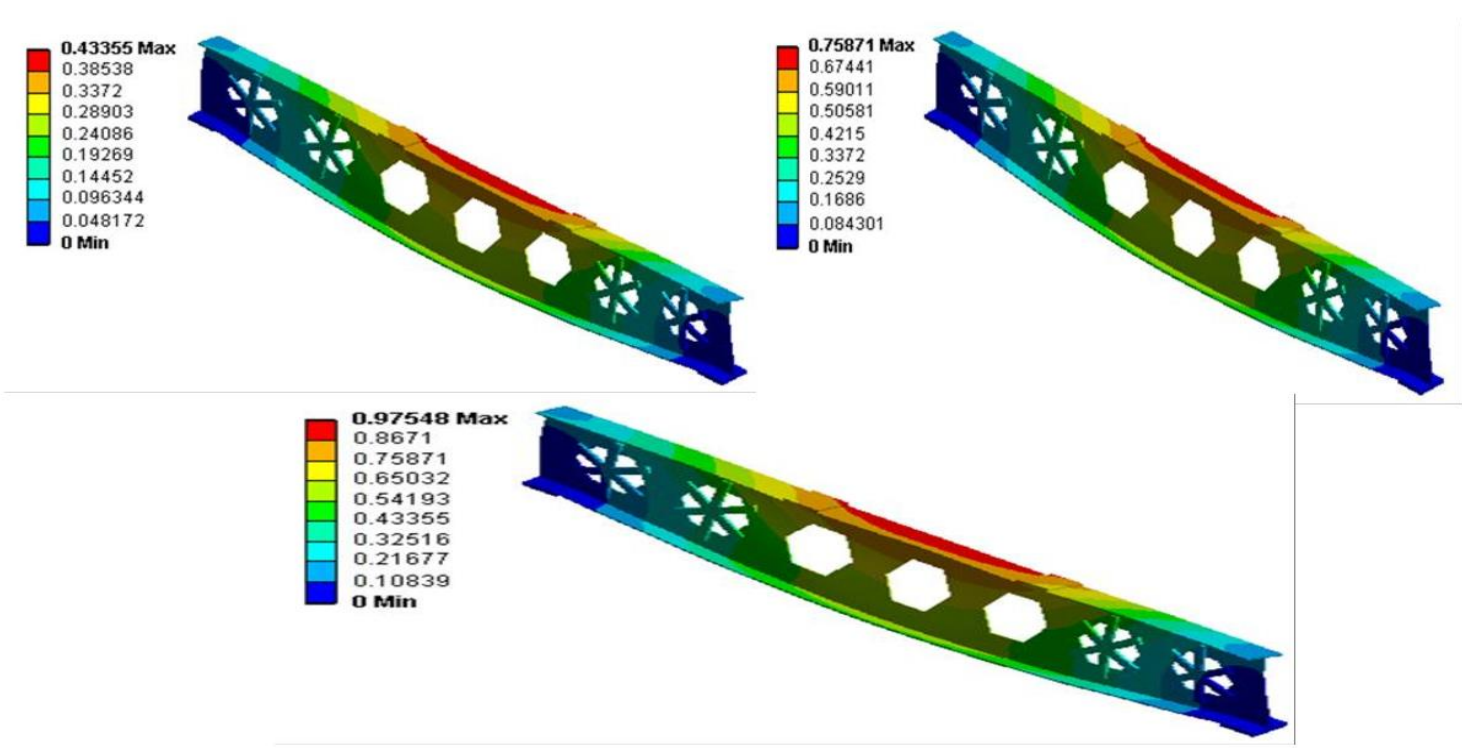

Figure 25 Deflection behaviour in case-2 and cycle -1, 2, 3

Deflection behaviour on case-3 with 3 cycles

The following graphs for case III are plotted between the deflection values of load Vs. A specimen used in the castellated beam IC 300 and provide in the second case deflection data seen in the graph and analysed as ANSYS images for cycles 1, 2, 3 as shown in Figures 26. 

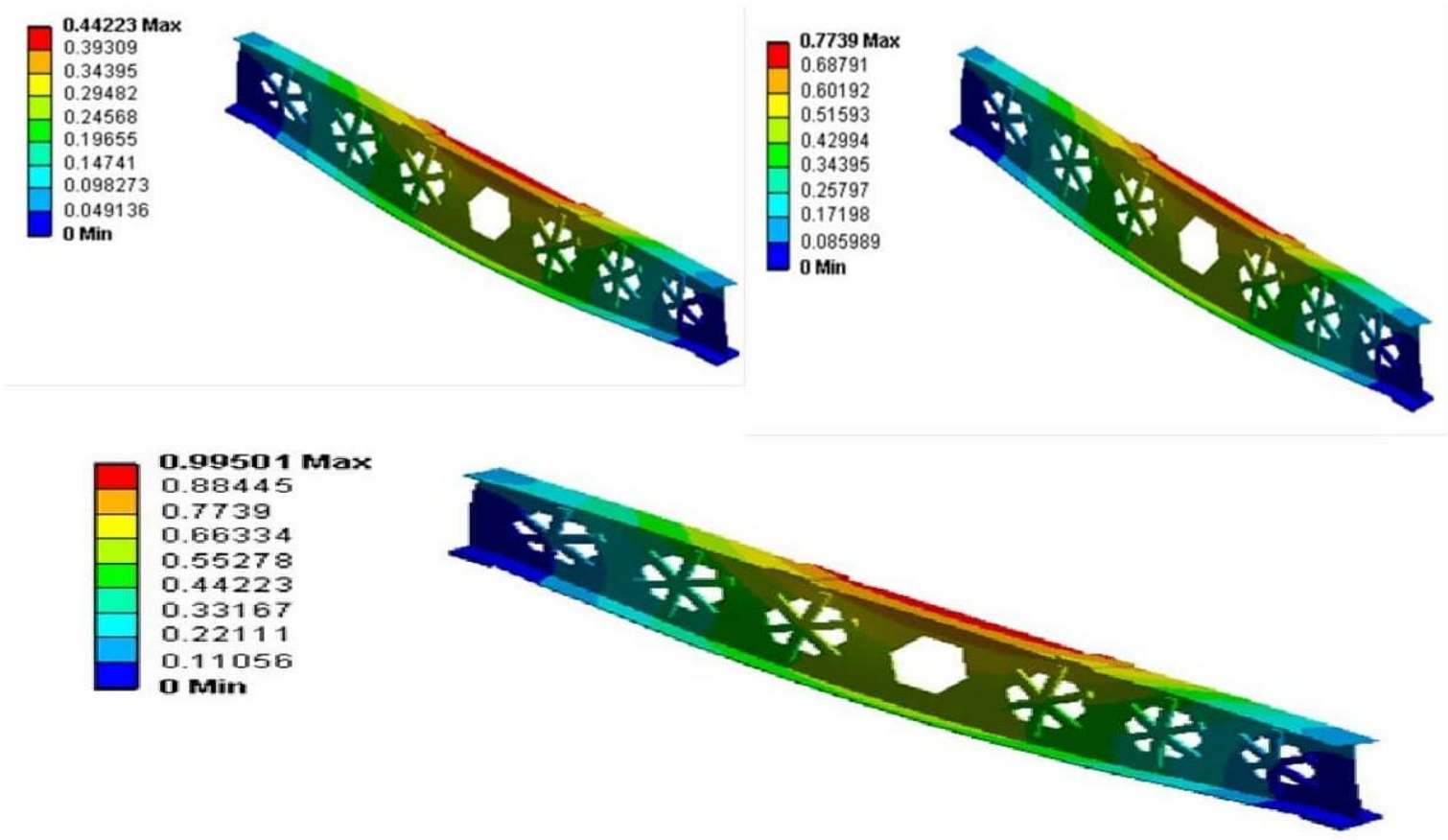

Figure 26 Deflection behaviour in case-3 and cycle -1, 2, 3

Equivalent stress and strain behaviour of the beam with 3 cases

This section is effective to approximate the deflection of the precast modular slab with a joint by reflecting the attached transmission length to the left and right sides of the initial cracked surface below the cracking moment and considering that cracking occurs on the UHSC when the failure load is reached. Because the tensile forces on the left and right sides of the cracked surface were shared by the steel reinforcements connected in the lapped splice, tensile stress in UHSC was minimised when the joint has been separated and UHSC is assumed to be noncracking until the specimen fails. Figure 27 indicates the average value attended in case $-\mathrm{I}$, case -II and case -III for Equal Stress Vs Strain activity analysis in the deflection. The combined graphical analyses in stress Vs strain analysis are shown in Figure 28. 


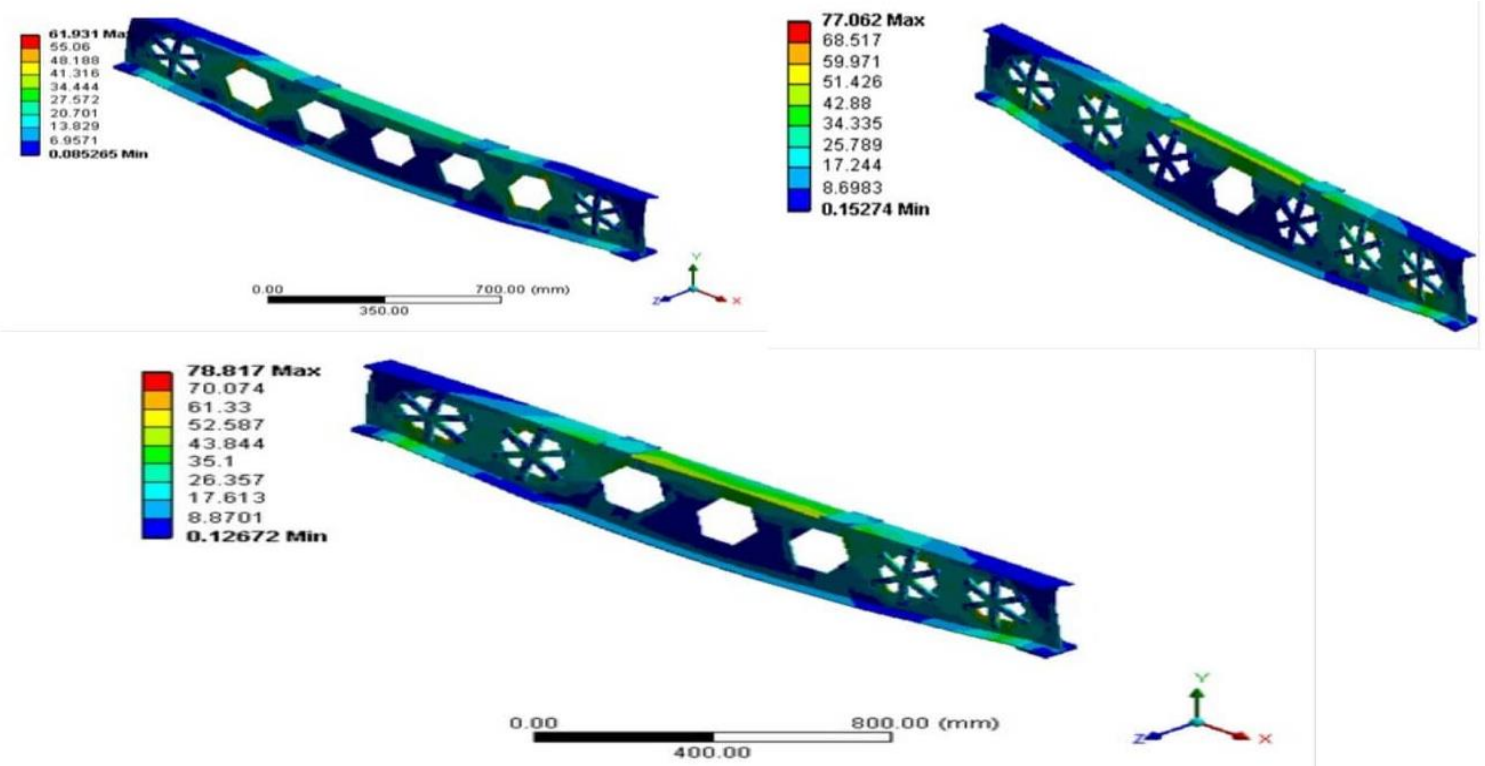

Figure 27 Equivalent Stress Vs Strain behaviour analysis in Case $1,2,3$

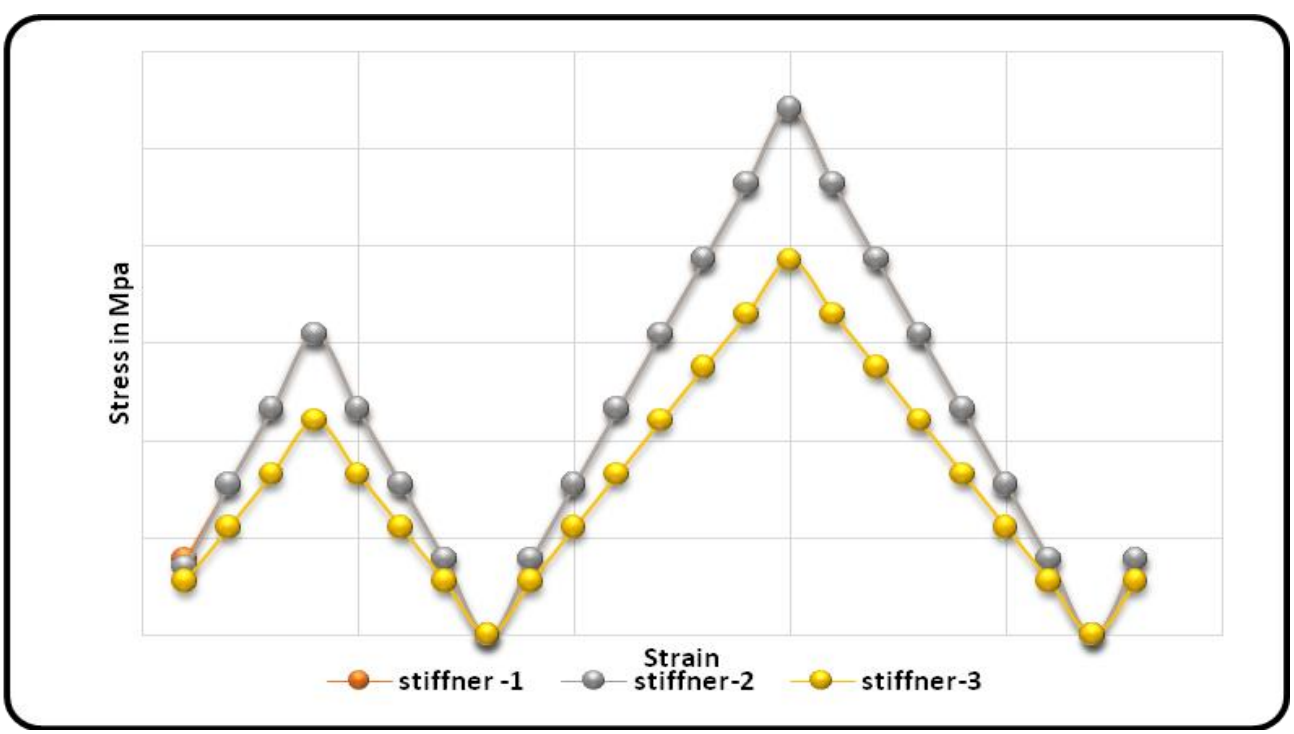

Figure 28 Graphical analyses of stress Vs strain behaviour for three cases

\section{Performance analysis}

In this section, the castellated beam with different cases (three cases) performances is efficiently analysed. Thus it includes the castellated beam tested with three cyclic loadings of forwarding and reverse direction by three cases.

Case-1 deflection analysis for reverse cyclic loading 
The division of the associated boundary stages determined the yield point of the extreme longitudinal reinforcement. The collapsing strain of the delineated concrete is critical for accurately predicting the cyclic behavior of reinforced concrete beam columns. The values of load applied and the deflections measured on castellated beam chassis specimen IC $300-$ Case-I (stiffeners are provided in one web hole at each end of the specimen) during the first, second and three cycles of forwarding cyclic loading are presented in Table 4.

Table 4 deflection analysis for reverse cyclic loading of case-1

\begin{tabular}{|l|l|l|l|l|l|l|l|l|l|l|}
\hline & \multicolumn{2}{l}{} & \multicolumn{2}{l|}{2} & \multicolumn{2}{l|}{2} & \multicolumn{3}{l|}{} \\
No. of Cycles & 1 & & & & & & & & \\
\hline Reverse Cyclic Loading (kN) & 18 & 9 & 0 & 45 & 36 & 27 & 72 & 63 & 54 \\
\hline & & & & & & & & & \\
Deflection (mm) & 1.93 & 1.25 & 0.37 & 4.01 & 3.56 & 2.93 & 6.16 & 5.63 & 5.13 \\
\hline
\end{tabular}

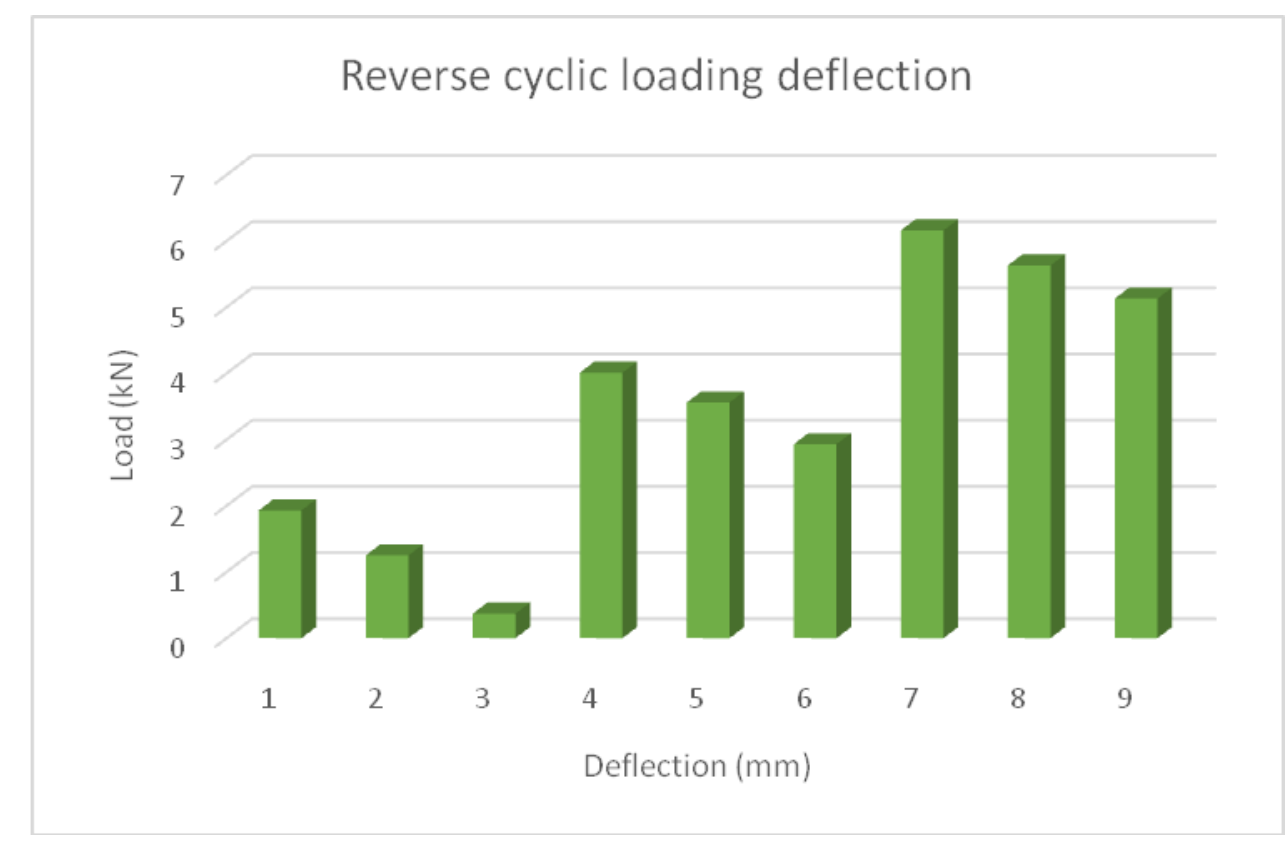

Figure 29 deflection analysis for reverse cyclic loading of case-1

The loads applied are 18, 9, 0 for first cycle, 45, 36, 27 for second cycle, and 72, 63, 54 for third cycle and the respective deflections are 1.93, 1.25, 0.37, 4.01, 3.56, 2.93, 6.16, 5.63 and $5.13 \mathrm{~mm}$. A mathematical model relating load and deflection has been developed and is presented in Figure 29. 
Case-1 deflection analysis for forwarding cyclic loading

The load and deflection values in respect of castellated beam specimen IC 300 (Case-I, stiffeners were provided in one web hole at each end of the beam) are presented in Table 5.

Table 5 deflection analysis for forwarding cyclic loading of case-1

\begin{tabular}{|l|l|l|l|l|l|l|l|l|l|}
\hline No. of Cycles & \multicolumn{2}{l|}{1} & \multicolumn{4}{l|}{2} & \multicolumn{3}{l|}{3} \\
\hline Forward Cyclic Loading & 9 & 18 & 17 & 9 & 18 & 27 & 9 & 18 & 27 \\
\hline Deflection & 0.55 & 1.72 & 2.48 & 1.23 & 1.87 & 2.55 & 1.66 & 2.35 & 3.05 \\
\hline
\end{tabular}

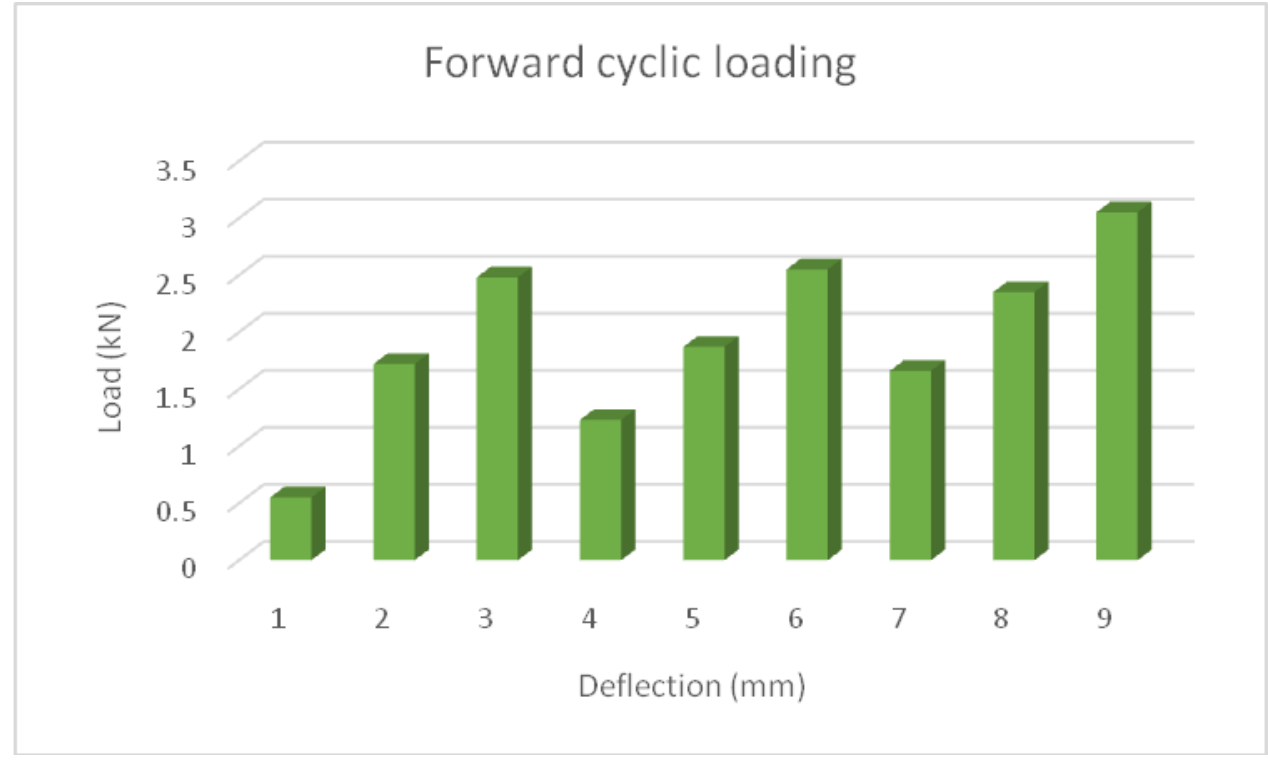

Figure 30 deflection analysis for forwarding cyclic loading of case1

In the three cycles of forwarding cyclic loading, the loads are applied gradually at an increment of $9 \mathrm{kN}$, beginning from $9 \mathrm{kN}$, going through $18 \mathrm{kN}, 27 \mathrm{kN}$, and the deflections that are measured corresponding to the applied loads are in the first cycle is $0.55,1.72,2.48$, the second cycle is $1.23 \mathrm{~mm}, 1.87 \mathrm{~mm}, 2.55 \mathrm{~mm}$, and the third cycle is $1.66,2.35,3.05$ respectively. A mathematical model has been developed bringing out the relation between load and deflection and is shown in Figure 30. 


\section{Case-2 deflection analysis for reverse cyclic loading}

Experimental tests are conducted on castellated beam chassis specimens IC 300 - Case-II where stiffeners are provided in two adjacent web holes at each end of the beam specimen. Three cycles (first, second, and third) of reverse cyclic loading are implemented.

Table 6 Deflection analysis for reverse cyclic loading of case-2

\begin{tabular}{|l|l|l|l|l|l|l|l|l|l|}
\hline No. of Cycles & \multicolumn{3}{l}{1} & \multicolumn{2}{l|}{2} & \multicolumn{3}{l|}{3} \\
\hline Reverse Cyclic Loading (kN) & 27 & 18 & 9 & 27 & 36 & 45 & 54 & 45 & 36 \\
\hline Deflection (mm) & 2.9 & 2.43 & 1.734 & 3.02 & 3.42 & 3.87 & 3.82 & 3.327 & 2.87 \\
\hline
\end{tabular}

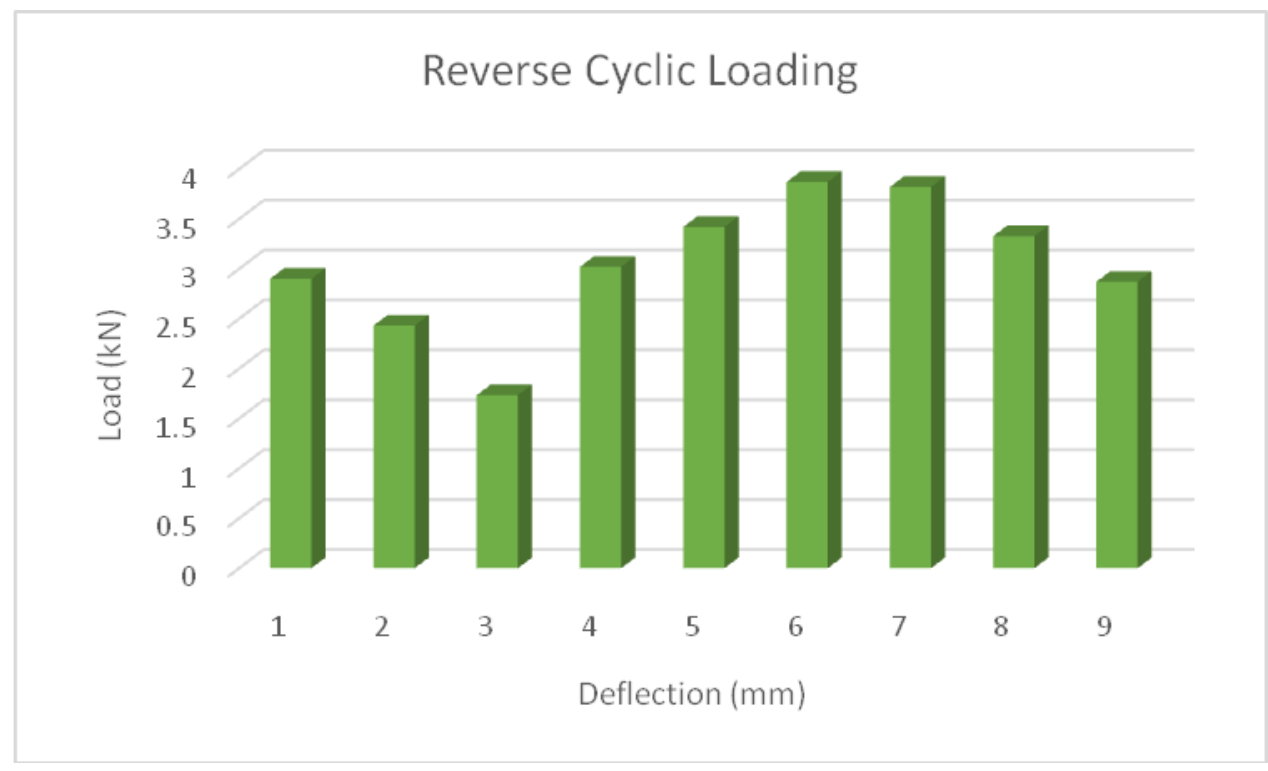

Figure 31 deflection analysis for reverse cyclic loading of case-2

In the three cycles of reversed cyclic loading, the loads are applied for the first cycle is 27,18 , 9, the second cycle is $27,36,45$ and third cycle is 54,45 , and 36 . The deflections corresponding to the applied loads were measured. The values of deflections are in first cycle $2.9,2.43,1.734$, second cycle is $3.02,3.42,3.87$, and the third cycle is $3.82,3.327$, and 2.87 respectively. The load and deflection data are presented in Table 6. A mathematical expression bringing out the relation between load and deflection has been obtained from the graph as shown in Figure 31. 
Case-2 deflection analysis for forwarding cyclic loading

The load and deflection values in respect of castellated beam chassis specimen IC 300 (CaseII - stiffeners were provided in two adjacent web holes at each end of the beam) under three cycles of forwarding cyclic loading are presented in Table 7.

Table 7 Deflection analysis for forwarding cyclic loading of case-2

\begin{tabular}{|c|c|c|c|c|c|c|c|c|c|}
\hline No. of Cycles & \multicolumn{3}{|l|}{1} & \multicolumn{3}{|l|}{2} & \multicolumn{3}{|l|}{3} \\
\hline $\begin{array}{l}\text { Forward Cyclic } \\
\text { Loading }\end{array}$ & 9 & 18 & 17 & 9 & 18 & 27 & 9 & 18 & 27 \\
\hline Deflection & 0.909 & 1.789 & 2.464 & 1.81 & 2.438 & 3.02 & 1.856 & 2.432 & 2.916 \\
\hline
\end{tabular}

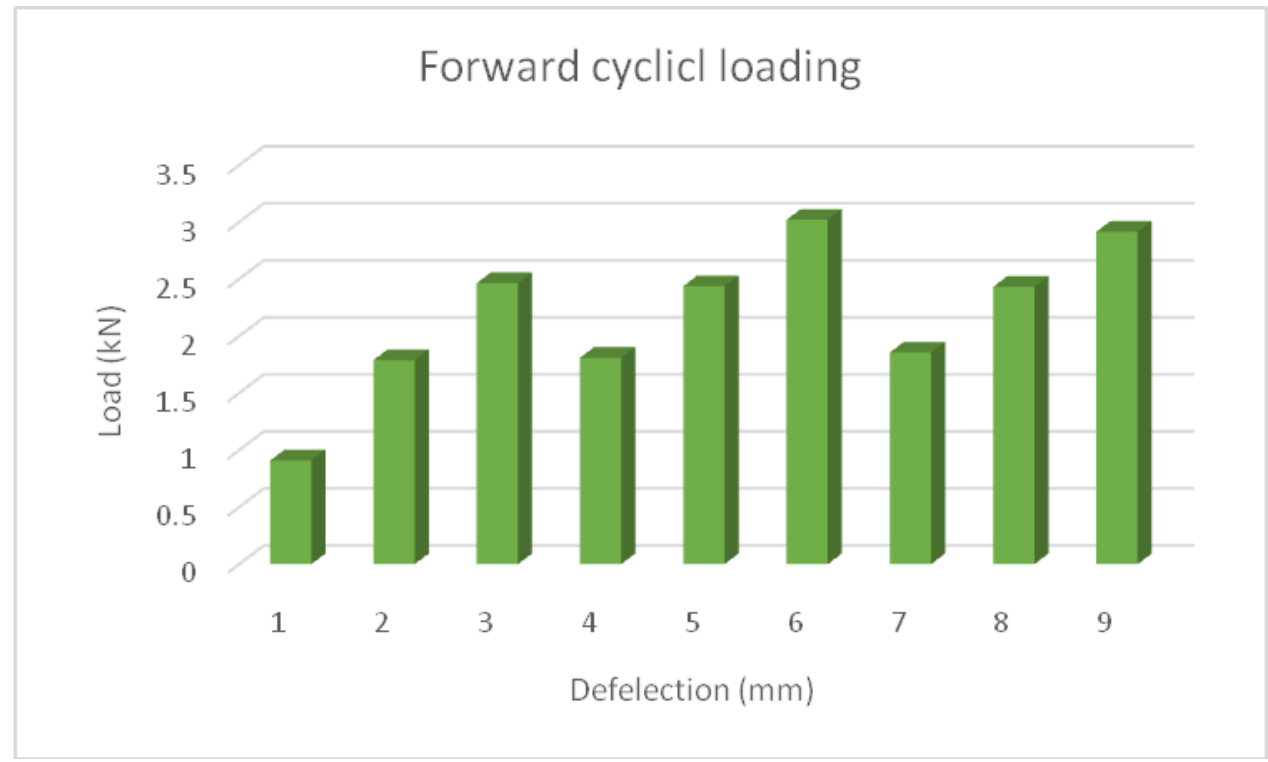

Figure 32 Deflection analysis for forwarding cyclic loading of case2

In the first cycle of forwarding cyclic loading, loads applied and the corresponding deflections are as follows: for first cycle $9 \mathrm{kN}-0.909 \mathrm{~mm}, 18 \mathrm{kN}-1.789 \mathrm{~mm}, 17 \mathrm{kN}-2.464 \mathrm{~mm}$, second cycle $9 \mathrm{kN}-1.81 \mathrm{~mm}, 18 \mathrm{kN}-2.438 \mathrm{~mm}, 17 \mathrm{kN}-3.02 \mathrm{~mm}$, and the third cycle is $9 \mathrm{kN}-1.856$ mm, $18 \mathrm{kN}-2.432 \mathrm{~mm}, 17 \mathrm{kN}-2.916 \mathrm{~mm}$. A mathematical expression connecting load and deflection, as shown in Figure 32, has been derived. 


\section{Case-3 deflection analysis for reverse cyclic loading}

Castellated beam chassis specimens of Case-III wherein stiffeners are provided in three consecutive web holes at each end of the beam specimen are subjected to three cycles (first, second, and third cycles) of loading. Each cycle involved both forward cyclic loading and reverse cyclic loading.

Table 8 Deflection analysis for reverse cyclic loading of case-3

\begin{tabular}{|l|l|l|l|l|l|l|l|l|l|}
\hline No. of Cycles & \multicolumn{3}{l}{1} & \multicolumn{3}{l|}{2} & \multicolumn{3}{l|}{3} \\
\hline Reverse Cyclic Loading (kN) & 27 & 18 & 9 & 63 & 54 & 45 & 72 & 63 & 54 \\
\hline Deflection (mm) & 2.24 & 1.14 & 0.65 & 5.16 & 4.54 & 3.86 & 6.36 & 5.48 & 4.51 \\
\hline
\end{tabular}

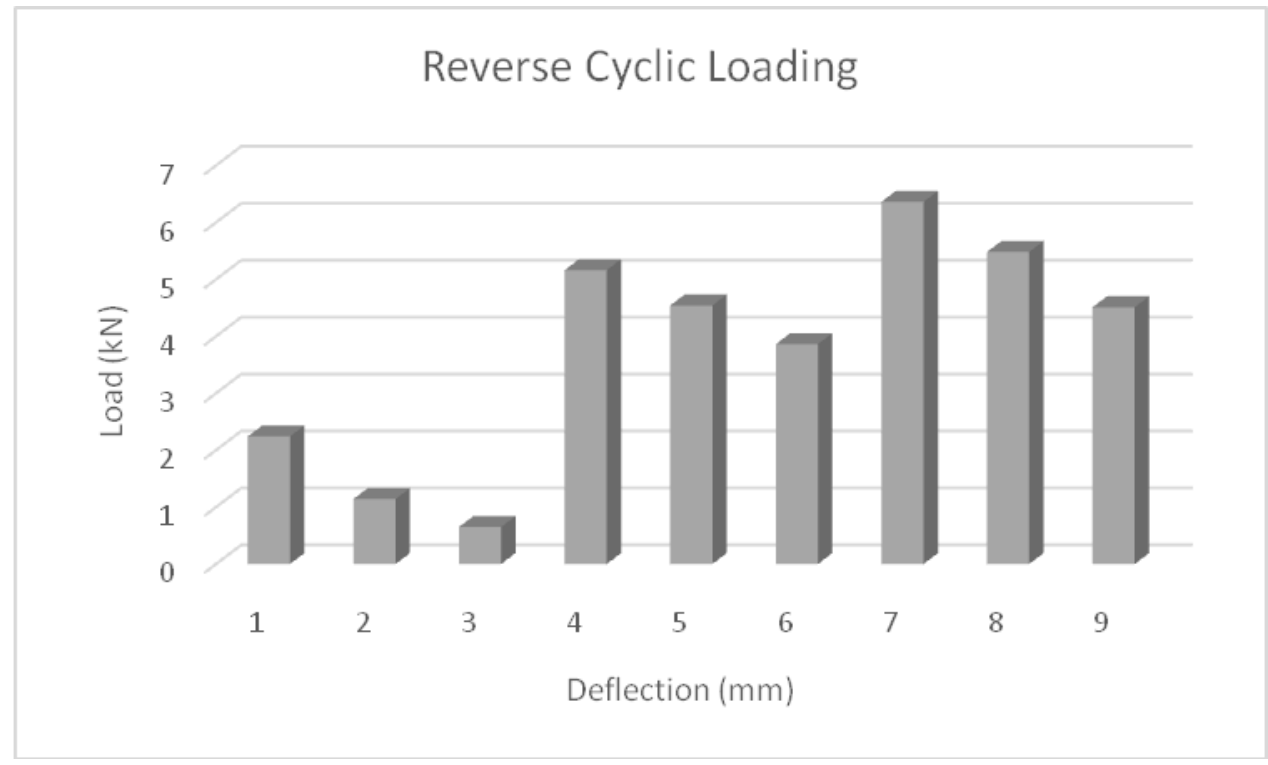

Figure 33 Deflection analysis for reverse cyclic loading of case-3

In respect of castellated beam chassis specimen IC 300 - Case III (stiffeners are provided in three consecutive web holes at each end of the specimen), under three cycle of reversed cyclic loading, the loads are applied at an increment of the first cycle is $27,18,9$, the second cycle is $63,54,45$ and third cycle is $72,63,54$ and the resultant deflections are the first cycle is 2.24 , $1.14,0.65$, the second cycle is $5.16,4.54,3.86$, third cycle is $6.36,5.48,4.51$ respectively. The 
load and deflection data are presented in Table 8 and the load vs. deflection graph appears in Figure 33.

\section{Case-3 deflection analysis for forwarding cyclic loading}

In respect of castellated beam chassis specimen IC 300 - Case III (stiffeners were provided in three consecutive web holes at each end of the specimen), under three cycle of forwarding cyclic loading, the loads applied are 9, 18, 27 and the corresponding deflections of the first cycle is $1.06,1.9,2.61$, the second cycle is $2.2,2.85,3.38$ and third cycle is $1.78,2.4,3.15$ respectively.

Table 9 Deflection analysis for forwarding cyclic loading of case-3

\begin{tabular}{|l|l|l|l|l|l|l|l|l|l|}
\hline No. of Cycles & \multicolumn{4}{l}{1} & \multicolumn{4}{l|}{2} & \multicolumn{3}{l}{3} \\
\hline Forward Cyclic Loading & 9 & 18 & 27 & 9 & 18 & 27 & 9 & 18 & 27 \\
\hline Deflection & 1.06 & 1.9 & 2.61 & 2.2 & 2.85 & 3.38 & 1.78 & 2.4 & 3.15 \\
\hline
\end{tabular}

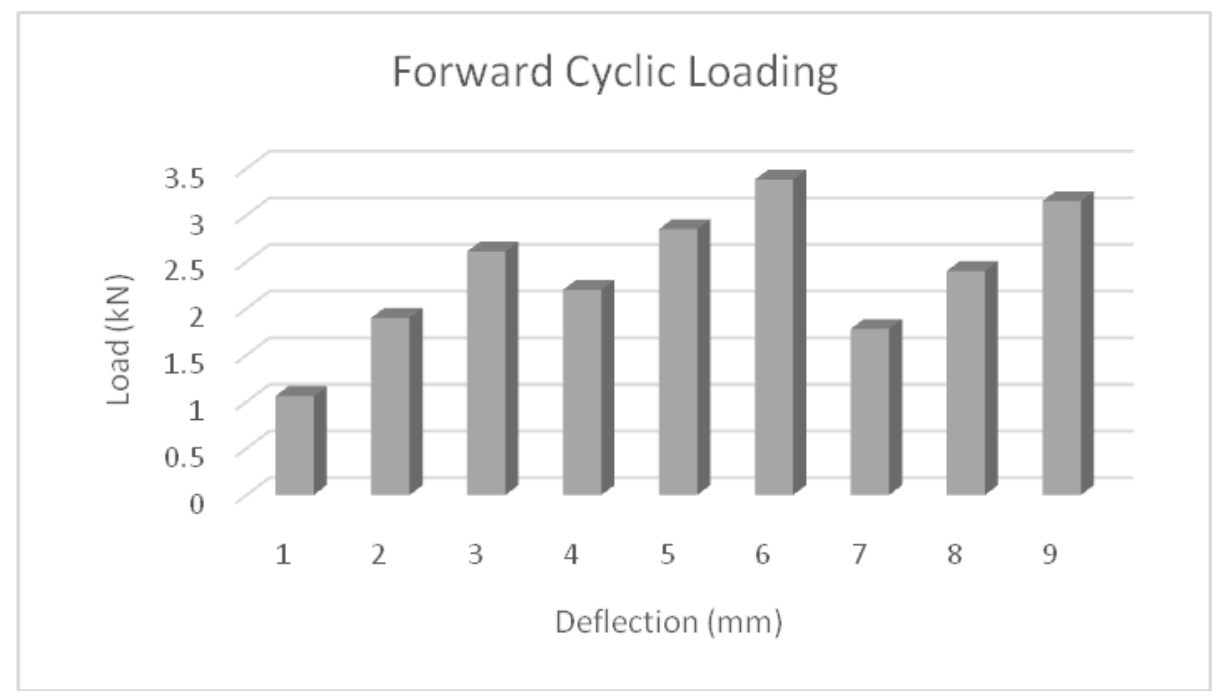

Figure 34 Deflection analysis for forwarding cyclic loading of case3

The load and deflection data are presented in Table 9 and the load vs. deflection graph appears in Figure 34.

\section{Maximum Deflection}


The maximum deflections shown by castellated beam chassis specimens IC 300 all three cases of fastening of stiffeners in web holes - under forwarding cyclic loading are depicted in the form of bar charts in figure 35 and figure 36 respectively.

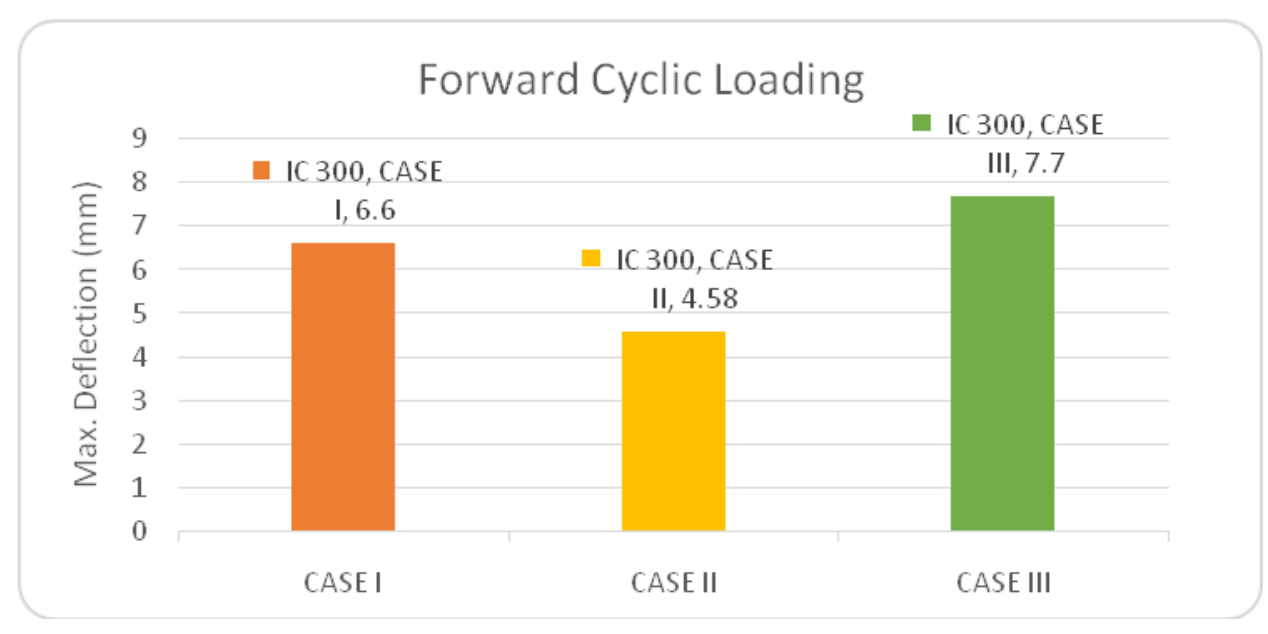

Figure 35 Maximum deflection of forwarding cyclic loading

From figure 35, it is observed that the castellated beam chassis specimen IC 300 - Case-II (stiffeners were provided at two adjacent web holes at each end of the specimen) has produced less deflection $(4.58 \mathrm{~mm})$ under forwarding cyclic loading as compared to the deflections produced by Case-I $(6.60 \mathrm{~mm})$ and Case-III $(7.70 \mathrm{~mm})$ specimens. Among the three cases of IC 300, Case-III (stiffeners were provided at three consecutive web holes at each end of the specimen) has shown the highest deflection $(7.70 \mathrm{~mm})$ under forwarding cyclic loading. 


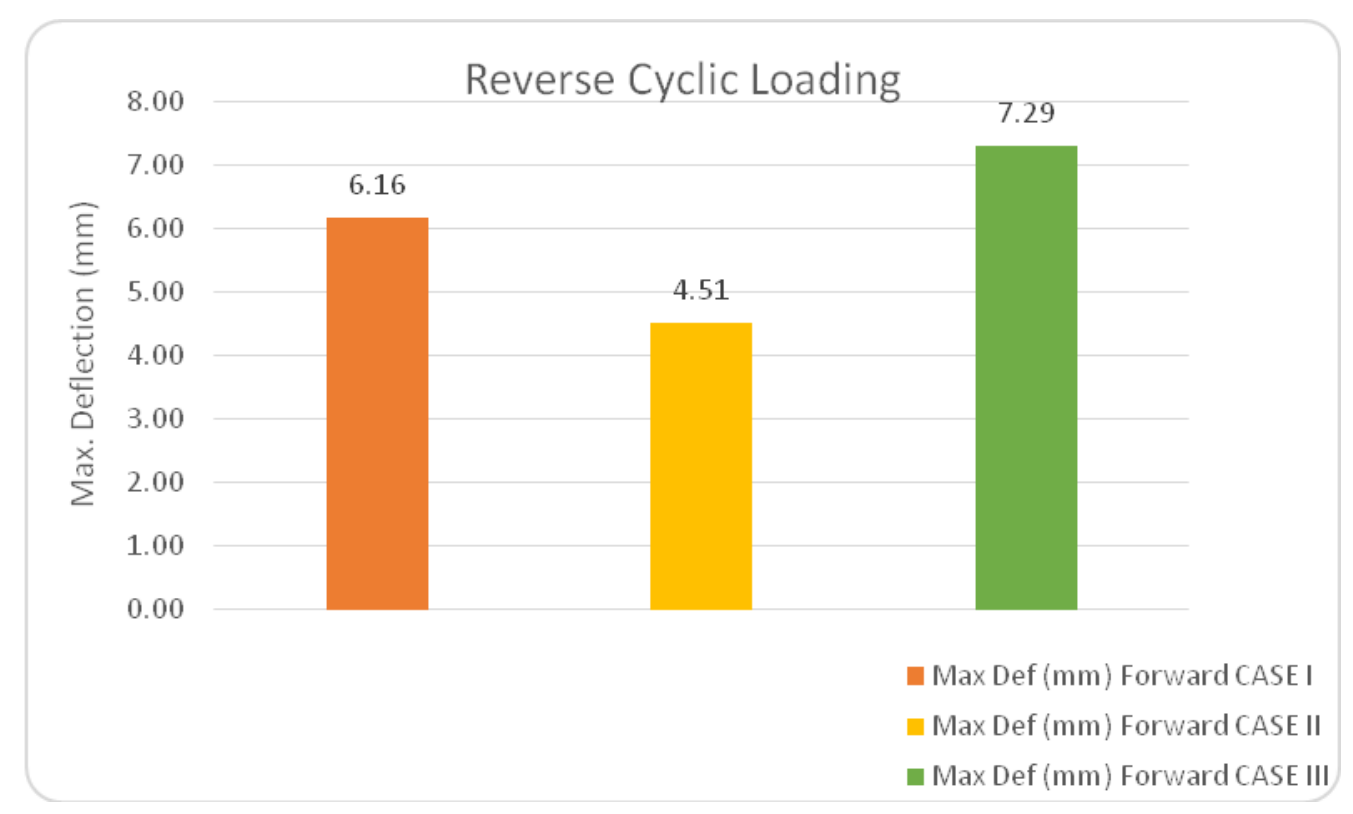

Figure 36 Maximum deflection of reverse cyclic loading

From Figure 36, it is observed that the castellated beam chassis specimen IC 300 - Case-II (stiffeners were provided at two adjacent web holes at each end of the specimen) has produced less deflection $(4.51 \mathrm{~mm})$ under reversed cyclic loading as compared to the deflections produced by Case-I $(6.16 \mathrm{~mm})$ and Case-III $(7.29 \mathrm{~mm})$ specimens. Among the three cases of IC 300, Case-III (stiffeners were provided at three consecutive web holes at each end of the specimen) has shown the highest deflection $(7.29 \mathrm{~mm})$ under reversed cyclic loading. 


\section{Comparison analysis}

This section described the competence of the research study based on the performances of the different steel section with ISMB 200.

Table 10 Comparison analysis of deflection

\begin{tabular}{|l|l|l|}
\hline Si.No & Steel section & Average Deflection $(\mathbf{m m})$ \\
\hline 1. & IC 225 (WOS) & 2.9 \\
\hline 2. & IC 225 (WDS) & 3.14 \\
\hline 3. & ISMB 150 & 4.04 \\
\hline 4. & ISMB 200 (present analysis) & 5.98 \\
\hline
\end{tabular}

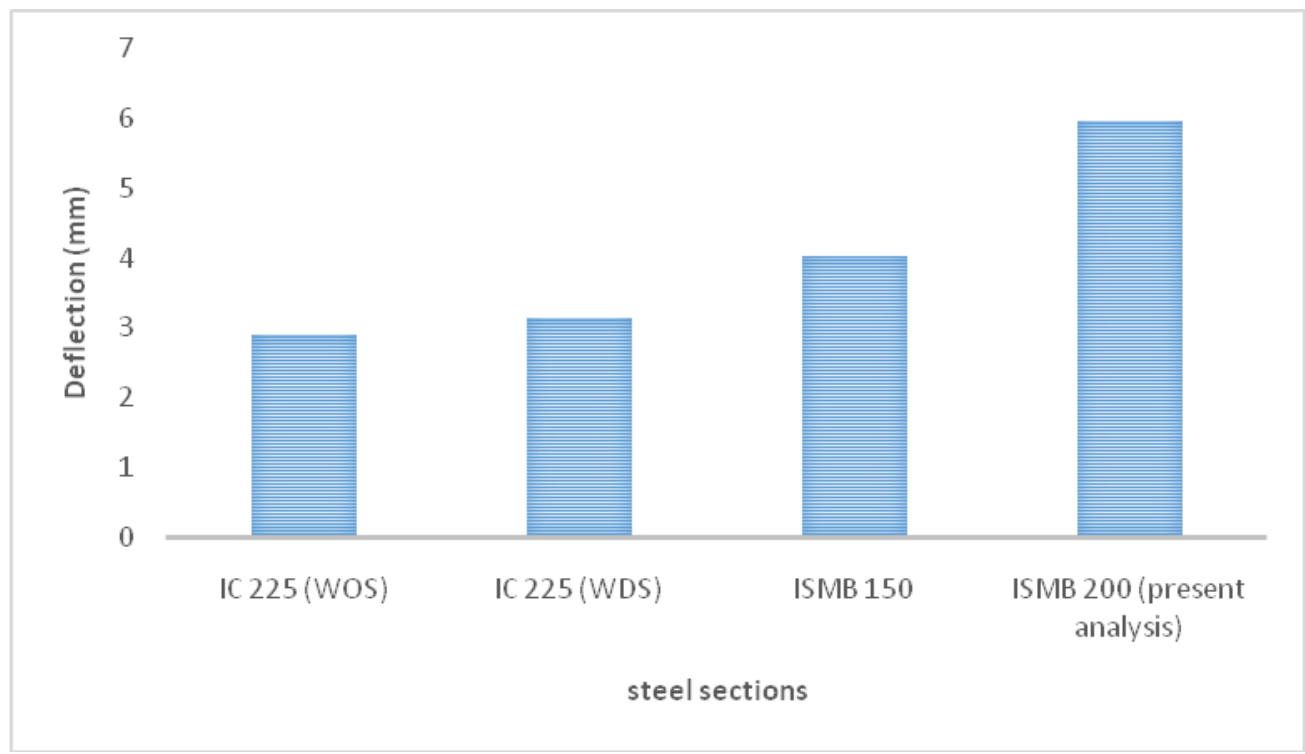

Figure 37 Comparison analysis of deflection 


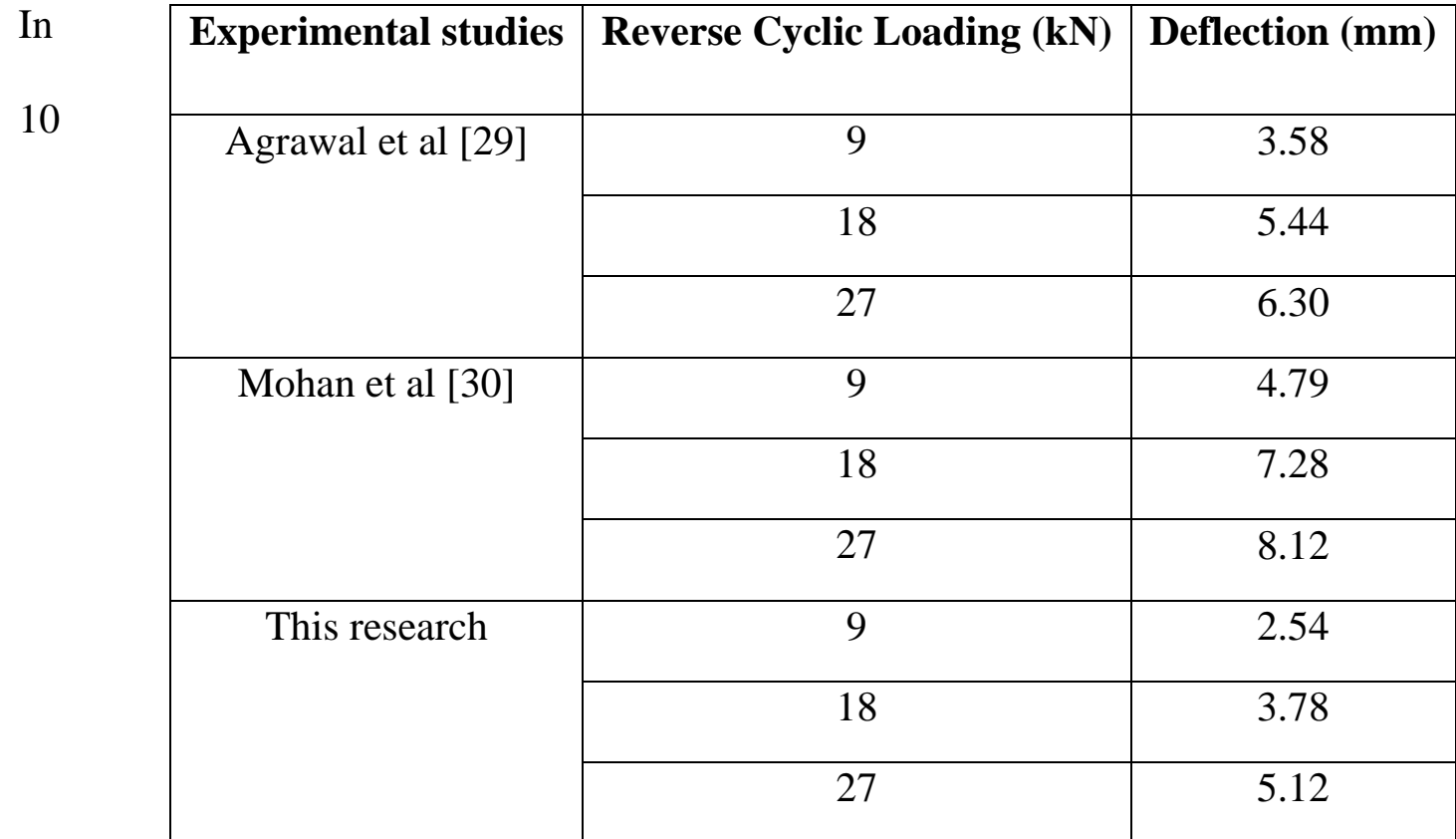

table

described the comparative analysis of different steel section such as IC 225- With Diagonal Stiffeners (WDS), IC 225-Without Stiffeners (WOS), ISMB 150, and ISMB 200 for corresponding average deflection is $2.9 \mathrm{~mm}, 3.14 \mathrm{~mm}, 4.04 \mathrm{~mm}$ and $5.98 \mathrm{~mm}$ respectively, which is illustrated in figure 37.

Table 11 Comparison analysis for deflection

In table 11 described the comparative analysis for various studies and their deflection value with reverse cyclic loading. Here the reverse cyclic loading is applied as 9, 18, and $27 \mathrm{kN}$ and corresponding deflection value for Agrawal et al [29] is 3.58, 5.44 and 6.30mm, Mohan et al [30] is $4.79,7.28$ and $8.12 \mathrm{~mm}$ at last this studies attains the deflection values is $2.54,3.78$ and $5.12 \mathrm{~mm}$. Thus it illustrates the proficiency of the research study at reverse cyclic loading performance at it accomplished the competent performance in deflection. Hence from the experimental analysis, it has been proven that the study of this research competently performs the investigation of castellated beam strength through the placement of a number of stiffeners on the beam chassis. This involves, on each side of the beam with one stiffener, two stiffeners and three stiffeners. Whereascyclic loading induced deflection $65 \%, 45 \%$ and $77 \%$ respectively for the case I, II and III. This shows the deflection of the beam case II decreases 
and for the case III deflection increases. This revealed the stiffeners provided on two end holes shows better performance rather than the stiffeners provided for three end holes on each end of the beams, thus it described the efficiency of the research study.

\section{CONCLUSION}

Several experiments have been carried out to investigate the castellated beams in which different studies have been adopted to predict the structure of the beams, such as experimental, analytical and computational. In their analysis of beam power, many of them require flexibility and are therefore very expensive. Besides that, by adding stiffeners and two opposite cyclic loads, the main objective of this research is to investigate the shear strength of the castellated beam. Although, due to its increase in size, the presence of web opening leads to various effects such as shear and deformation, the castellated beam gains its advantage without any extra weight. As the hole corners and the load application level have also increased, the tension concentration increases. The web opening can then be applied along with the amount of stiffener placements to decrease the concentration of tension and increase the shear strength of the castellated beam chassis. While the forward cyclic loading caused deflection for cases I, II and III of $65 \%, 45 \%$ and $77 \%$ respectively. This revealed that the stiffeners provided on two end holes showed better output instead of the stiffeners provided on each end of the beams for three end holes. 


\section{REFERENCES}

[1].Sudarshan Kale, Prof. Vishwajeet Kadlag, Dr. Sanjay Kulkarni, 2018. Study Behaviour of Castellated Beam with Diagonal Stiffeners within and Outside the Opening by Using ABAQUS Software, International Research Journal of Engineering and Technology (IRJET) 05(07).

[2].Jamadar, A.M. and Kumbhar, P.D, 2015. Parametric Study of Castellated Beam with Circular and Diamond Shaped Openings. International Research Journal of Engineering and Technology 2: 715-722.

[3].Patil, S.A. and Kumbhar. P.D., 2016. Comparative Study of Transverse Stiffeners and Stiffeners along the Opening Edge used for Castellated Beam. International Journal of Innovative Research in Science, Engineering and Technology 5: 8516- 8522.

[4]. Tsavdaridis, K.D. and Galiatsatos, G., 2015. Assessment of Cellular Beams with Transverse Stiffeners and Closely Spaced Web Openings. Thin-Walled Structures 94: 636650.

[5]. Amin Mohebkhah and Mojtaba G. Azandariani, 2015. Lateral- Torsional Buckling Of Delta Hollow Flange Beams Under Moment Gradient, Thin-Walled Structures 86: 167173.

[6]. Delphine Sonck and Jan Belis, 2015. Lateral-Torsional Buckling Resistance of Cellular Beams, Journal of Constructional Steel Research 105: 119-128.

[7]. Konstantinos Daniel Tsavdaridis, James J. Kingman and Vassilli V. Toropov, 2015. Application of Structural Topology Optimisation to Perforated Steel Beams", Computers and Structures 158: 108-123.

[8]. Durif, S. and Bouchair, A. 2016. Analytical Model To Predict The Resistance of Cellular Beams With Sinusoidal Openings, Journal of Constructional Steel Research 121: 80-96.

[9]. ANSYS User's Manual. (2017). ANSYS Mechanical APDL Technology Demonstration Guide, Release 18.1, Canonsburg, USA: ANSYS Inc.

[10]. Badke-Neto, A., Calenzani, A.F.G. and Ferreira, W.G. 2015. Study of methods for the design of cellular composite steel and concrete beams, Ibracon structures and material Journal 8(6): 827-859.

[11]. Ellobody, E. and Young, B. (2015). Nonlinear analysis of composite castellated beams with profiled steel sheeting exposed to different fire conditions, Journal of Constructional Steel Research 113: 247-260.

[12]. Erdal, F., Tunca, O. and Tas, S. 2015. Nonlinear finite element analysis of optimally designed steel cellular beams, Research on Engineering Structures and Materials 2(2): 5966.

[13]. Gao, K., Gao, W., Wu, B.H. and Song, C.M. 2019. Nondeterministic dynamic stability assessment of Euler-Bernoulli beams using Chebyshev surrogate model, Applied Mathematical Modelling 66: 1-25.

[14]. Jovic, M. 2015. Lateral torsional buckling analysis of multiple laterally restrained Ibeams in bending, Master thesis A-2015.102. Eindhoven University of Technology Department of the Built Environment Structural Design.

[15]. Kim, B., Li, L. and Edmonds, A. 2016. Analytical Solutions of Lateral-Torsional Buckling of Castellated Beams, International Journal of Structural Stability and Dynamics, 16(8): 1-16 (1550044).

[16]. Kwani, S. and Wijaya, P.K. 2017. Lateral torsional buckling of castellated beams analyzed using the collapse analysis, Procardia Engineering 171: 813- 820 
[17]. Martins, C.H., Fer-reira, F.P.V., Rossi, A. and Trentini, E.V.W. 2017. Numerical Analysis of Physical and Geometrical Imperfections in Cellular Beams, Open Journal of Civil Engineering 7: 116-129.

[18]. Panedpojaman, P. 2015. Investigation on lateral torsional buckling resistance of ec3 for cellular beam, International Journal of Advances in Mechanical and Civil Engineering 2(4) ISSN: 389-399.

[19]. Pourbehi, P. and Pirmoz, A. 2015. Shear response of castellated steel beams." International Journal of Steel Structures 15(2): 389-399.

[20]. Sonck, D. and Belis, J. 2016. Lateral-Torsional Buckling Resistance of Castellated Beams, Journal of Constructional Steel Research 105: 119-128.

[21]. Yuan, W.B., Yu, N.T., Bao, Z.S. and Wu, L.P. 2016. Deflection of castellated beams subjected to uniformly distributed transverse loading, International Journal of Steel Structures 16(3): 813-821.

[22]. Setiyawan, P., Maimunah, D. and Wulandari, D. 2019. The Effect of Hole Width on Full Height Rectangular Opening Castellated Steel Beam with Diagonal Stiffener Concerning Its Flexural Capacity. JACEE (Journal of Advanced Civil and Environmental Engineering) 2(2): 76-84.

[23]. Al-Thabhawee, H.W. and Mohammed, A.A. 2019. Reinforcing the Octagonal Web Openings of Castellated Beam by Steel Rings. Al-Qadisiyah Journal for Engineering Sciences 12(1): 7-16.

[24]. Anupriya, B, Jagadeesan, K. and Saranya. 2016. Effect of stiffeners on Castellated Beam, Asian Journal of Research in Social Sciences and Humanities 6: 30-37.

[25]. Sahar S. Elaiwi, S.S., Boksun. Kim and Long-yuan. Li. 2019. Linear and Nonlinear Buckling Analysis of Castellated Beams, International Journal of Structural and Civil Engineering Research 8(2).

[26]. Stalin, B., Ravichandran, M., Kannan, C.R. and Moorthi, K.S. 2019. Design and Analysis of Stringer on the Chassis Frame in Load Carrying Vehicle, In Advances in Manufacturing Technology, Springer, Singapore 219-225.

[27]. Al-Thabhawee, H.W.A. and Al-Kannoon, M.A.A. 2018. Improving Behavior of Castellated Beam by Adding Spacer Plat and Steel Rings, Journal of University of Babylon for Engineering Sciences 26(4): 331-344.

[28]. Lei, J.S., Yuan, W.B. and Li, L.Y., 2017. Axial compression buckling of castellated columns at elevated temperatures, International Journal of Structural Stability and Dynamics 17(03): 1750034.

[29]. Agrawal, Vimlesh \& Bhatt, Dr. 2017. A Design Comparison of Castellated Beam for Different Parameters. 10.29007/cz65.

[30]. Mohan, R. and Prabhakaran, P. 2015. Experimental analysis to compare the deflection of Steel beams with and without web openings, International Journal of Research in Engineering and Technology 4(09): 373-377. 